Published in final edited form as:

Nature. 2015 April 9; 520(7546): 192-197. doi:10.1038/nature14362.

\title{
Fatty acid carbon is essential for dNTP synthesis in endothelial cells
}

\author{
Sandra Schoors ${ }^{\# 1,2}$, Ulrike Bruning ${ }^{\# 1,2}$, Rindert Missiaen ${ }^{1,2}$, Karla CS Queiroz $^{1,2}$, Gitte \\ Borgers $^{1,2}$, Ilaria Elia ${ }^{3,4}$, Annalisa Zecchin ${ }^{1,2}$, Anna Rita Cantelmo ${ }^{1,2}$, Stefan Christen ${ }^{3,4}$, \\ Jermaine Goveia ${ }^{1,2}$, Ward Heggermont ${ }^{5}$, Lucica Goddé ${ }^{1,2}$, Stefan Vinckier $^{1,2}$, Paul P. Van \\ Veldhoven $^{6}$, Guy Eelen ${ }^{1,2}$, Luc Schoonjans ${ }^{1,2}$, Holger Gerhardt ${ }^{7,8,9}$, Mieke Dewerchin ${ }^{1,2}$, \\ Myriam Baes $^{10}$, Katrien De Bock ${ }^{1,2,11}$, Bart Ghesquière ${ }^{1,2}$, Sophia Y. Lunt ${ }^{12}$, Sarah-Maria \\ Fendt $^{3,4}$, and Peter Carmeliet ${ }^{1,2}$ \\ ${ }^{1}$ Laboratory of Angiogenesis and Neurovascular link, Department of Oncology, University of \\ Leuven, Leuven, B-3000, Belgium \\ ${ }^{2}$ Laboratory of Angiogenesis and Neurovascular link, Vesalius Research Center, VIB, Leuven, \\ B-3000, Belgium \\ ${ }^{3}$ Laboratory of Cellular Metabolism and Metabolic Regulation, Department of Oncology, \\ University of Leuven, Leuven, B-3000, Belgium \\ ${ }^{4}$ Laboratory of Cellular Metabolism and Metabolic Regulation, Vesalius Research Center, VIB, \\ Leuven, B-3000, Belgium \\ ${ }^{5}$ Center for Molecular \& Vascular Biology, KU Leuven; Division of Clinical Cardiology, UZ Leuven, \\ B-3000, Belgium \\ ${ }^{6}$ Laboratory of Lipid biochemistry and protein interactions, University of Leuven, B-3000, Leuven, \\ Belgium \\ ${ }^{7}$ Vascular Patterning Laboratory, Department of Oncology, University of Leuven, Leuven, B-3000, \\ Belgium \\ ${ }^{8}$ Vascular Patterning Laboratory, Vesalius Research Center, VIB, Leuven, B-3000, Belgium \\ 9Integrative Vascular Biology Laboratory, Max Delbrück Center for Molecular Medicine, Berlin, \\ Germany \\ ${ }^{10}$ Laboratory of Cell Metabolism, Department of pharmaceutical and pharmacological sciences, \\ University of Leuven, Leuven, B-3000,Belgium
}

Reprints and permissions information is available at www.nature.com/reprints.Users may view, print, copy, and download text and data-mine the content in such documents, for the purposes of academic research, subject always to the full Conditions of use:http:// www.nature.com/authors/editorial_policies/license.html\#terms

Correspondence and requests for materials should be addressed to PC (peter.carmeliet@ vib-kuleuven.be) or SMF (sarahmaria.fendt@vib-kuleuven.be).

Author contributions: SS, UB, RM, KQ, GB, IE, AZ, ARC, SC JG, WH, LG, SV, PPVV, GE, LS, MD, MB, KDB, BG, SYL, SMF and PC contributed to the performance of the experiments and/or analysis of the data; HG provided advice; SS, UB, KDB, SMF and PC designed the experiments; SS, MD, KDB, SMF and PC wrote the paper; and PC conceptualized the study. All authors discussed the results and commented on the manuscript.

Competing financial interests: PC declares to be named as inventor on patent applications, claiming subject matter related to the results described in this paper. 
${ }^{11}$ Exercise Physiology Research Group, Department of Kinesiology, University of Leuven, Leuven, B-3001, Belgium

${ }^{12}$ Department of Biochemistry and Molecular Biology, Michigan State University, East Lansing, Michigan, USA

\# These authors contributed equally to this work.

\section{Abstract}

The metabolism of endothelial cells (ECs) during vessel sprouting remains poorly studied. Here, we report that endothelial loss of CPT1a, a rate-limiting enzyme of fatty acid oxidation (FAO), caused vascular sprouting defects due to impaired proliferation, not migration of ECs. Reduction of FAO in ECs did not cause energy depletion or disturb redox homeostasis, but impaired de novo nucleotide synthesis for DNA replication. Isotope labeling studies in control ECs showed that fatty acid carbons substantially replenished the Krebs cycle, and were incorporated into aspartate (a nucleotide precursor), uridine monophosphate (a precursor of pyrimidine nucleoside triphosphates) and DNA. CPT1a silencing reduced these processes and depleted EC stores of aspartate and deoxyribonucleoside triphosphates. Acetate (metabolized to acetyl-CoA, thereby substituting for the depleted FAO-derived acetyl-CoA) or a nucleoside mix rescued the phenotype of CPT1a-silenced ECs. Finally, CPT1 blockade inhibited pathological ocular angiogenesis, suggesting a novel strategy for blocking angiogenesis.

Angiogenesis relies on the proliferation and migration of endothelial cells (ECs) ${ }^{1}$. The importance of EC proliferation for expansive growth of the vascular network has long been recognized $^{2}$. While numerous molecules regulating vessel sprouting have been identified ${ }^{3}$, little is known about the role of metabolism. We recently reported that ECs generate $85 \%$ of their ATP for vessel sprouting via glycolysis ${ }^{4}$. Fatty acid oxidation (FAO) has been linked in various cell types to ATP production and to ROS scavenging during cellular stress, but apart from a few earlier in vitro reports ${ }^{5}$, the role and importance of FAO in ECs during angiogenesis in vivo is undefined.

By shuttling long chain fatty acids into mitochondria, carnitine palmitoyltransferase 1 (CPT1) constitutes a rate-limiting step of FAO. Oxidation of palmitate generates acetylCoA, which fuels the TCA cycle. Apart from generating ATP, the TCA cycle also provides precursors for macromolecule synthesis, necessary for proliferation. However, fatty acids have not yet been shown to function as carbon sources for biosynthetic processes. In this study, we elucidated the role of FAO in ECs during angiogenesis, and studied how FAO determines EC behavior.

\section{FAO stimulates vessel sprouting via EC proliferation}

To study the role of mitochondrial FAO in vessel sprouting, we silenced CPT1a, the most abundant CPT1 isoform in human umbilical venous ECs (HUVECs), which lowered levels of CPTla mRNA and protein and reduced FAO flux (Extended Data Fig. 1a-f). In contrast, silencing of CPT1c, expressed at lower levels (Extended Data Fig. 1a), did not affect FAO (Extended Data Fig. 1g). As similar data were obtained in other EC subtypes (Extended Data Fig. 1d,h), we used HUVECs (denoted as "ECs") for our study. 
Using EC spheroids, CPT1a silencing $\left(\mathrm{CPT} 1 \mathrm{a}^{\mathrm{KD}}\right)$ decreased vessel sprout length and numbers (Fig. 1a-c; Extended Data Fig. 1i). This defect was due to decreased EC proliferation since $\mathrm{CPT} 1 \mathrm{a}^{\mathrm{KD}}$ reduced proliferation and had only minimally additive effects in mitomycin C-treated mitotically inactivated ECs (Fig. 1c-f; Extended Data Fig. 1i,j). By contrast, $\mathrm{CPT} 1 \mathrm{a}^{\mathrm{KD}}$ did not affect EC migration or motility (Fig. 1g-i; Extended Data Fig. $1 \mathrm{k})$. Similar results were obtained when silencing long-chain acyl-CoA dehydrogenase (ACADVL), another FAO gene (Extended Data Fig. 11-o). Additional evidence for a role of FAO in vessel sprouting was provided by overexpression of CPT1a $\left(\mathrm{CPT1a}{ }^{\mathrm{OE}}\right)$, which yielded opposite results to those obtained by $\mathrm{CPT} 1 \mathrm{a}^{\mathrm{KD}}$ (Extended Data Fig. 1p-t). Thus, CPT1a-driven FAO regulates EC proliferation during vessel sprouting.

To study the effects of endothelial CPT1a-deficiency on vessel formation in vivo, we used Cpt1 ${ }^{\text {lox/lox }}$ mice intercrossed with VE-Cadherin(PAC)-Cre ${ }^{\mathrm{ERT} 2}\left(\mathrm{CPT} 1 \mathrm{a}^{\Delta \mathrm{EC}}\right)$ mice (Extended Data Fig. 1u). Isolectin-B4 staining of retinal vessels of transgenic pups at P5 revealed that EC loss of CPT1a diminished the number of vascular branch points, and reduced radial expansion of the vascular plexus (Fig. 2a-e). This was not caused by increased vessel regression (Fig. 2f-h), but by reduced EC proliferation (Fig. 2i-k). Furthermore, CPT1 $\mathrm{a}^{\triangle \mathrm{EC}}$ mice had normal numbers of filopodia (Fig. 21-n) and vessel maturation (Fig. 2o-p; Extended Data Fig. 1v). Thus, impaired angiogenesis in CPT1a $\mathrm{a}^{\Delta \mathrm{EC}}$ mice was due to EC proliferation defects.

\section{CPT1 $\mathrm{a}^{\mathrm{KD}}$ does not cause ATP or redox imbalance}

To explore via which mechanism FAO regulates EC proliferation, we studied if $\mathrm{CPT} 1 \mathrm{a}^{\mathrm{KD}}$ impaired EC proliferation by causing energy stress due to ATP depletion. However, $\mathrm{CPT} 1 \mathrm{a}^{\mathrm{KD}}$ did not lower ATP levels, nor did it affect the energy charge or ADP/ATP ratio (Fig. 3a,b; Extended Data Fig. 2a). This was not surprising, as FAO generated only $5 \%$ of the total amount of ATP in ECs ${ }^{4}$. Oxygen consumption (OCR) coupled to ATP synthesis was modestly reduced (Fig. 3c), but could not explain the sprouting defect, as blocking mitochondrial ATP production with oligomycin failed to affect sprouting of control and CPT1 $\mathrm{a}^{\mathrm{KD}}$ ECs, suggesting that CPT1 $\mathrm{a}^{\mathrm{KD}}$ impaired sprouting independently of mitochondrial ATP production (Fig. 3d; Extended Data Fig. 2b). Additional experiments confirmed that CPT1 $\mathrm{a}^{\mathrm{KD}}$ ECs were not in energy stress (Extended Data Fig. 2c,d).

We also explored whether $\mathrm{CPT} 1 \mathrm{a}^{\mathrm{KD}}$ impaired vessel sprouting by altering redox balance. CPT1 $\mathrm{a}^{\mathrm{KD}}$ increased ROS levels by only $20 \%$, an increase reported to enhance EC proliferation ${ }^{6}$, without affecting the percentage of oxidized glutathione or disturbing redox homeostasis (Fig. 3e,f). Also, lowering ROS levels by using N-acetyl-cysteine (NAC) did not restore vessel sprouting upon CPT1a silencing (Fig. 3g; Extended Data Fig. 2e). Finally, $\mathrm{CPT} 1 \mathrm{a}^{\mathrm{KD}}$ did not compromise EC survival and did not increase levels of oxidative DNA damage markers (Extended Data Fig. 2f-j). Thus, CPT1a ${ }^{\mathrm{KD}}$ did not impair vessel sprouting by inducing toxic ROS levels.

\section{FAO is used for de novo synthesis of nucleotides}

We thus considered a novel role for FAO in EC proliferation and explored whether FAO regulated the production of biomass building blocks. Supplementing EC monolayers with 
$\left[\mathrm{U}_{-}{ }^{13} \mathrm{C}\right]$-palmitate or an algal $\left[\mathrm{U}_{-}{ }^{13} \mathrm{C}\right]$-fatty acid mix revealed that carbons from fatty acids provided a significant fraction of the total carbon fueling the TCA cycle intermediates and TCA cycle-derived amino acids, in fact comparably to the contribution of carbons from $\left[\mathrm{U}_{-}{ }^{13} \mathrm{C}\right]$-glutamine and $\left[\mathrm{U}_{-}{ }^{13} \mathrm{C}\right]$-glucose (Fig. $\left.4 \mathrm{a}-\mathrm{c}\right){ }^{7}$. This was unexpected as many cancer cell types rely almost exclusively on glucose and glutamine to fuel the TCA cycle ${ }^{8}$. $\mathrm{CPT} 1 \mathrm{a}^{\mathrm{KD}}$ also lowered the cellular pool size of citrate, aspartate and glutamate (Fig. $4 \mathrm{~d}$ ).

Since TCA intermediates are used for the synthesis of biomass precursors, and inhibition of FAO limited the supply of these TCA intermediates, we explored if CPT1 ${ }^{\mathrm{KD}}$ impaired protein and/or nucleotide synthesis. CPT1 $\mathrm{a}^{\mathrm{KD}}$ did however not impair de novo protein synthesis (Fig. 4e) and did not consistently alter intracellular amino acid levels (Fig. 4d). Also, CPT1 $\mathrm{a}^{\mathrm{KD}}$ still lowered EC proliferation when protein synthesis was reduced by cycloheximide (Fig. 4f), suggesting that a decrease of de novo protein synthesis did not prevent CPT1a silencing to establish its proliferation defect.

Given that aspartate is a precursor of nucleotides and its levels were reduced upon $\mathrm{CPT} 1 \mathrm{a}^{\mathrm{KD}}$, we explored if fatty acid-derived carbons were used for de novo ribonucleotide synthesis. Indeed, label from $\left[\mathrm{U}_{-}{ }^{14} \mathrm{C}\right]$-palmitate was incorporated into RNA in control ECs, and this process was decreased upon CPT1a ${ }^{\mathrm{KD}}$ (Fig. $4 \mathrm{~g}$ ). However, despite this, CPT1a ${ }^{\mathrm{KD}}$ ECs did not have reduced RNA levels and pools of ribonucleotides (rNTPs) (Fig. 4h,i), presumably because of compensatory production by salvage pathways. Thus, insufficient RNA synthesis did not cause the proliferation defect of CPT1 ${ }^{\mathrm{KD}}$ ECs.

We therefore assessed if impaired de novo deoxyribonucleotide synthesis caused the proliferation defect of $\mathrm{CPT} 1 \mathrm{a}^{\mathrm{KD}} \mathrm{ECs}$. Indeed, label from $\left[\mathrm{U}^{1}{ }^{14} \mathrm{C}\right]$-palmitate was incorporated into DNA, and this was reduced upon CPT1a silencing (Fig. $4 \mathrm{j}$ ). As CPT1 $\mathrm{a}^{\mathrm{KD}}$ also decreased de novo DNA synthesis (Fig. 1d), we hypothesized that FAO blockade reduced aspartate levels and thereby compromised de novo deoxyribonucleotide biosynthesis. Indeed, labeled carbons from $\left[\mathrm{U}_{-}{ }^{13} \mathrm{C}\right]$-palmitate were incorporated in the pyrimidine precursors uridine monophosphate (UMP) and uridine-5' ${ }^{\prime}$-triphosphate (UTP), and this incorporation was reduced upon CPT1a silencing (Fig. 4k,1; Extended Data Fig. 3a). Moreover, quantification of deoxyribonucleotide (dNTP) levels confirmed that CPT1 $\mathrm{a}^{\mathrm{KD}}$ lowered the intracellular levels of all pyrimidine (dCTP, dTTP) and purine deoxyribonucleotides (dATP, dGTP) needed for DNA replication (Fig. 4m). Thus, in contrast to the retained rNTP levels, CPT1a ${ }^{\mathrm{KD}}$ depleted the pool of dNTPs.

To functionally confirm that the effect of $\mathrm{CPT} 1 \mathrm{a}^{\mathrm{KD}}$ depends on reduced de novo nucleotide synthesis, we inhibited de novo synthesis of nucleotides by methotrexate (MTX) and 5fluorouracil (5FU), which reduced vessel sprouting in control but no longer in $\mathrm{CPT} 1 \mathrm{a}^{\mathrm{KD}}$ cells (Fig. 4n,o; Extended Data Fig. 3b,c). Thus, CPT1 $\mathrm{a}^{\mathrm{KD}}$ reduced sprouting mainly via inhibition of de novo deoxyribonucleotide synthesis.

To confirm the role of fatty acid derived carbons for nucleotide synthesis, we supplemented $\mathrm{CPT} 1 \mathrm{a}^{\mathrm{KD}}$ cells with acetate (which is converted to acetyl-CoA). Treatment of CPT1 $\mathrm{a}^{\mathrm{KD}}$ ECs with acetate completely restored the levels of aspartate and dNTPs (Fig. 5a,b). Furthermore, $\mathrm{CPT} 1 \mathrm{a}^{\mathrm{KD}}$ and control cells incorporated comparable amounts of [U- $\left.{ }^{13} \mathrm{C}\right]-$ 
acetate into UMP and UTP (Fig. 5c,d). Functionally, acetate rescued the sprouting defect of CPT1a ${ }^{\text {KD }}$ ECs (Fig. 5e; Extended Data Fig. 3d-g). Also, blockade of the ATP synthase did not prevent this rescue, indicating that acetate was not used for the production of ATP but instead for the synthesis of biomass (Extended Data Fig. 3h,i).

Supplementation of a mix of nucleosides or dNTPs also fully rescued the sprouting defect of $\mathrm{CPT} 1 \mathrm{a}^{\mathrm{KD}}$ vessels, indicating that FAO blockade impaired nucleotide synthesis (Fig. 5f;

Extended Data Fig. 3j,k). Notably, acetate or the nucleoside mix were unable to rescue the $\mathrm{CPT} 1 \mathrm{a}^{\mathrm{KD}}$ sprouting defect upon mitotic inactivation of $\mathrm{CPT} 1 \mathrm{a}^{\mathrm{KD}} \mathrm{ECs}$, indicating that their effect relied on stimulating EC proliferation (Extended Data Fig. 31; not shown). Thus, CPT1a-driven FAO is critical for de novo deoxyribonucleotide synthesis to ensure EC proliferation during sprouting.

\section{Glucose partly compensates for FAO loss}

Nucleotides can also be synthesized from glucose and glutamine ${ }^{9}$, so we asked if ECs would compensate for the loss of FAO using these nutrients. CPT1 $\mathrm{a}^{\mathrm{KD}}$ increased the oxidation of glucose but not of glutamine (Extended Data Fig. $3 \mathrm{~m}, \mathrm{n}$ ), and increased $\left[\mathrm{U}-{ }^{13} \mathrm{C}\right]$-glucose incorporation into citrate and aspartate, whereas $\left[\mathrm{U}^{-13} \mathrm{C}\right]$-glutamine incorporation into citrate and asparate was not/neglegibly altered (Fig. 5g; Extended Data Fig. 3o). The activity of pyruvate dehydrogenase and pyruvate carboxylase was increased in CPT1a ${ }^{\mathrm{KD}}$ ECs (Fig. 5h$\mathrm{j}$ ), which can contribute to the increase in glucose oxidation. Nonetheless, this compensation was insufficient to rescue the proliferation defect of $\mathrm{CPT} 1 \mathrm{a}^{\mathrm{KD}} \mathrm{ECs}$, indicating that fatty acids are irreplaceable for DNA replication in ECs.

\section{Do other cells use fatty acids for DNA synthesis?}

To assess the broader relevance of FAO's role in deoxyribonucleotide synthesis, we studied $\left[\mathrm{U}-{ }^{13} \mathrm{C}\right]$-palmitate contribution to citrate in a panel of normal and malignant proliferating cells. Fibroblasts (and to a certain extent pericytes) but no other primary cells incorporated substantial amounts of fatty acid-derived carbon into citrate (Fig. 6a). Except for the breast cancer (T47D, MCF7) and a lung cancer (A549) cell line (known to rely on FAO for ATP and NADPH production ${ }^{10}$ ), fatty acids contributed minimally to citrate production (Fig. 6a). Remarkably, even when these cancer cells incorporated fatty acid-derived carbons into citrate, they incorporated them to a much lesser extent into DNA (Fig. 6b), implying that fatty acid-derived carbons entering the TCA cycle were used for other purposes than deoxyribonucleotide synthesis. In fact, only fibroblasts incorporated similar amounts of fatty acid-derived carbons into DNA than ECs (Fig. 6b).

\section{Inhibition of CPT1a impairs angiogenesis}

Pharmacological agents with FAO-blocking activity are being used clinically ${ }^{11}$. To explore if pharmacological blockade of CPT1 reduced pathological angiogenesis, we used etomoxir, an irreversible inhibitor of mitochondrial long-chain FAO. Etomoxir reduced FAO and EC proliferation, but not migration in vitro (Extended Data Fig. 4a-c). In vivo, etomoxir induced similar retinal vascular defects as CPT1a deficiency in ECs (Extended Data Fig. 4d-g) and 
reduced pathological angiogenesis in a model of retinopathy of prematurity (ROP) (Fig. 6ce). The mechanistic model of our findings is represented in Fig. $6 \mathrm{f}$.

\section{Discussion}

The novelty of this study relates to several observations. First, FAO is critical for vessel sprouting in vivo, more importantly than expected based on earlier reports ${ }^{5}$. Second, FAO affects proliferation, not migration of ECs, which caused vessel sprouting defects. Unlike PFKFB3-driven glycolysis, which affects EC proliferation and migration ${ }^{4}$, FAO selectively regulates EC proliferation, indicating that distinct metabolic pathways control distinct EC functions during vessel sprouting. Third, we discovered an unknown role of fatty acidderived carbons in de novo nucleotide synthesis for DNA replication in ECs. Our results indicate that FAO promotes de novo deoxyribonucleotide synthesis by providing carbons for the production of aspartate and glutamate. The fact that aspartate is a direct carbon donor for the synthesis of the pyrimidine nucleobase (Extended Data Fig. 3a) and that the pool of aspartate was reduced in $\mathrm{CPT} 1 \mathrm{a}^{\mathrm{KD}} \mathrm{ECs}$ explain why pyrimidine $\mathrm{dNTP}$ levels were reduced. But aspartate and glutamate also serve as nitrogen source for the production of the nucleobase of pyrimidines and purines. This explains why the synthesis of purine dNTPs was also impaired upon FAO blockade. Interestingly, of other primary and malignant cell types tested, only ECs and fibroblasts used substantial amounts of fatty acid carbons for DNA synthesis, even though certain cancer cell lines incorporated fatty acid-derived carbons in the TCA cycle.

Fatty acids were irreplaceable for DNA synthesis, but not for protein and RNA synthesis. A possibility is that $\mathrm{CPT} 1 \mathrm{a}^{\mathrm{KD}}$ ECs maintained RNA levels by producing rNTPs via nucleotide salvage. Indeed, quiescent / hypo-proliferative cell types (CPT1 $\mathrm{a}^{\mathrm{KD}} \mathrm{ECs}$ are hypoproliferative) rely primarily on nucleotide salvage rather than on de novo nucleotide synthesis to synthesize RNA ${ }^{12}$. By contrast, proliferating cells switch on de novo synthesis of dNTPs to duplicate their DNA genome ${ }^{13}$. Support for the notion that ECs use nucleotide salvage primarily for RNA synthesis is provided by evidence that incorporation of carbons from hypoxanthine (a nucleotide salvage intermediate) was higher in RNA than DNA (Extended Data Fig. 3p). This may explain why FAO blockade affected levels of dNTPs but not/less of rNTP levels. A recent study on the role of pyruvate kinase (PK) isoenzymes documented that PKM1 expression reduced incorporation of ${ }^{13} \mathrm{C}$-label from $\left[\mathrm{U}_{-}{ }^{13} \mathrm{C}\right]$ glucose in UMP and decreased dNTP levels and cell proliferation, yet did not alter rNTP levels ${ }^{14}$, illustrating that the production of rNTPs and dNTPs is regulated differently.

Fourth, we identified that fatty acid-derived carbons entering the TCA cycle are used for biomass production. This was unexpected since evidence in rapidly proliferating cancer cells indicated that glucose and glutamine are utilized as primary carbon source for de novo deoxyribonucleotide synthesis 8,14 . The utilization of fatty acids for biomass production is however not unprofitable. Indeed, given that fatty acids are a much richer carbon source than glucose or glutamine, use of fatty acids is an efficient mechanism to generate nucleotides. Finally, pharmacological CPT1 blockade reduced pathological angiogenesis, which may hint to an underappreciated therapeutic potential of lowering FAO for the inhibition of pathological angiogenesis. 


\section{Experimental Methods}

\section{Chemicals and reagents}

Collagen type 1 (rat tail) was from Millipore or from PureCol® (bovine) (Advanced Biomatrix, USA). The CPT1a inhibitor (+)-etomoxir sodium salt hydrate was purchased from CNIO Carlos III Therapies. Mitomycin C (MitoC), sodium palmitate, dimethyl sulfoxide (DMSO), NAC, sodium acetate, oligomycin, cycloheximide, cytidine, adenine, guanosine, methotrexate, carnitine, dNTP mix and tamoxifen were from Sigma-Aldrich (Bornem, Belgium). 5-fluorouracil (TEVA Pharma Belgium) was obtained from the pharmacy of the university hospital Leuven. Nucleoside mix was from Millipore (Belgium) $)^{15}$. Hoechst 33342 and L-homopropargylglycine (HPG) were from Molecular Probes and L-glutamine and penicillin/streptomycin were from Gibco ${ }^{\circledR}$ (Invitrogen, Life Technologies, Ghent, Belgium). Uniformly labeled [U- $\left.{ }^{13} \mathrm{C}\right]$-potassium palmitate, $\left[\mathrm{U}_{-}{ }^{13} \mathrm{C}\right]-$ acetate, $\left[\mathrm{U}_{-}{ }^{13} \mathrm{C}\right]$-glucose, $\left[\mathrm{U}^{1}{ }^{13} \mathrm{C}\right]$-glutamine and $\left[\mathrm{U}_{-}{ }^{13} \mathrm{C}\right]$-algal fatty acid mix were obtained from Cambridge isotope laboratories, Inc. $\left[\mathrm{U}_{-}{ }^{14} \mathrm{C}\right]$-palmitate, $\left[9,10-{ }^{3} \mathrm{H}\right]$-palmitate, $\left[6-{ }^{14} \mathrm{C}\right]-$ D-glucose, $\left[8-{ }^{14} \mathrm{C}\right]$-hypoxanthine and $\left[{ }^{3} \mathrm{H}\right]$-thymidine were from Perkin Elmer.

\section{Cell culture}

$P_{\text {RIMARY }} C_{\text {ELLS: }}$ Human umbilical vein endothelial cells (HUVECs) were freshly isolated from different donors as described ${ }^{16}$ (with approval of medical ethical committee KULeuven/ UZLeuven and informed consent obtained from all subjects), regularly tested for mycoplasma and used between passage 1 and 5. HUVECs were cultured in M199 medium (1 mg/ml D-glucose) from Gibco ${ }^{\circledR}$ (Invitrogen, Life Technologies, Ghent, Belgium) supplemented with 20\% fetal bovine serum (FBS) Biochrom GmbH (Germany), 2 mM Lglutamine, $30 \mu \mathrm{g} / \mathrm{l}$ endothelial cell growth factor supplements (EGCS), 10 units/ml heparin (Sigma), $100 \mathrm{IU} / \mathrm{ml}$ penicillin and $100 \mu \mathrm{g} / \mathrm{ml}$ streptomycin or in endothelial basal medium (EBM-2) supplemented with endothelial growth medium SingleQuots (Promocell, Germany). In all experiments, HUVECs were always used as single-donor cultures. Human aortic ECs (HAECs) and adult human dermal blood microvascular ECs (HMVEC-dBlAd) were either from Clonetics, Lonza (Braine-l'Alleud, Belgium) or isolated from umbilical cords for arterial ECs or from placenta for microvascular ECs, and were cultured in the recommended medium supplemented with SingleQuots (EGM-2 or EGM-2 MV; Clonetics, Lonza, Braine-l'Alleud, Belgium). Human pericytes were isolated from human placenta using gentleMACS tissue dissociator (Miltenyi Biotec) and incubation with collagenase $0.2 \%$ (GIBCO) and Dnase $80 \mathrm{U} / \mathrm{ml}$ (Life technologies) for $30 \mathrm{~min}$ at $37^{\circ} \mathrm{C}$ followed by Percoll gradient 5 (GE Healthcare) centrifugation, or from human adipose tissue using collagenase $0.2 \%$ in $0.9 \% \mathrm{NaCl}$ and $2 \mathrm{mM} \mathrm{CaCl}_{2}$ for $1 \mathrm{hr} 37^{\circ} \mathrm{C}$. Thereafter, the cell suspension was immunomagnetically sorted by using CD31 and CD146 antibodies conjugated with microbeads (Miltenyi Biotec). $\mathrm{CD} 146^{+} / \mathrm{CD} 31^{-}$sorted cells were seeded in aMEM plus $10 \%$ FBS and $5 \mathrm{nM}$ PDGFBB. Human T cells: Peripheral blood mononuclear cells (PBMCs) were isolated from whole blood by Ficoll-Paque Plus (Amersham Biosciences) density gradient centrifugation. PBMCs were collected, washed with cold PBS and subsequently used for naive T-cell isolation. Naive T-cells were isolated with a pan Tcell isolation kit (MACS Myltenyi Biotec). After isolation, naïve T-cells were seeded in plates coated with anti-CD3 antibody 5ug/ml, anti-CD28 $(0.5 \mathrm{ug} / \mathrm{ml})$ and IL-2 $(10 \mathrm{ng} / \mathrm{ml})$ 
were added to the medium. All cell preparations were used in experiments as single donor cultures. Murine fibroblasts were freshly isolated from lungs of FVB mice and cultured and used between passage 1 and 5. Briefly, dissected lungs were chopped and digested in a solution of $2 \mathrm{mg} / \mathrm{ml}$ collagenase (Sigma blend L, Sigma-Aldrich) in RPMI media from Gibcoß (Invitrogen, Life Technologies, Ghent, Belgium) containing 2.5\% fetal bovine serum (FBS), 10mM HEPES, $2 \mathrm{mM}$ glutamine, $100 \mathrm{IU} / \mathrm{ml}$ penicillin and $100 \mu \mathrm{g} / \mathrm{ml}$ streptomycin $\left(5 \mathrm{ml} /\right.$ lung) for 1 hour at $37^{\circ} \mathrm{C}$. Organoids were pelleted at $1,100 \mathrm{rpm}$, washed four times with digestion solution and then plated into standard tissue culture flasks in DMEM/F12 medium from Gibco ${ }^{\circledR}$ (Invitrogen, Life Technologies, Ghent, Belgium) containing $5 \%$ fetal bovine serum (FBS), $2 \mathrm{mM}$ glutamine, $100 \mathrm{IU} / \mathrm{ml}$ penicillin and 100 $\mu \mathrm{g} / \mathrm{ml}$ streptomycin. The day after isolation, the medium was refreshed. Cells were then routinely maintained in $5 \% \mathrm{CO}_{2}$ and $95 \%$ air at $37^{\circ} \mathrm{C}$ and the medium was replaced every second day. ES CELL: G4 ES cells were routinely passaged every 2-3 days onto freshly prepared Mitomycin C arrested feeder layers, and were refed daily with fresh ES cell culture medium consisting of $500 \mathrm{ml}$ Knockout DMEM medium (Life Technologies), supplemented with $2 \mathrm{mM} \mathrm{L}$-glutamine (Life Technologies), 90ml fetal bovine serum (Biochrom BmgH), MEM nonessential amino acids 100× (GIBCO/Invitrogen), $0.01 \mathrm{mM} \beta$-mercaptoethanol (Sigma-Aldrich), $1 \mathrm{mM}$ sodium pyruvate (GIBCO/Invitrogen), penicillin /streptomycin 100x (Life Technologies), and 2000 U/ml Leukemia Inhibitory Factor (Merck Millipore). Prior to testing whether ES cells use fatty acids for DNA synthesis they were replated at least 3 times on gelatinized dishes without any feeders. Doing so, all feeder cells were selectively removed from the culture dishes, resulting in 100\% pure undifferentiated ES cell cultures. TUMOR CELL LNEE: Murine melanoma B16 clone F10.9 (obtained from American Type Culture Collection, ATCC; LGC Standards, Molsheim Cedex, France) and PancO2 murine pancreatic carcinoma cells (provided by B. Wiedenmann, Charité, Berlin, Germany) were cultured in RPMI containing 10\% FBS. MCF7 (human breast cancer), HCT116 (human colon carcinoma), MDA-MB-468 (human breast carcinoma cells), T47D (human ductal breast epithelial tumor cells), DU145 (human prostate cancer cells), 143B (human osteosarcoma cells), A549 (human lung carcinoma cells) were cultured in DMEM containing 10\% FBS, $2 \mathrm{mM}$ glutamine, $100 \mathrm{IU} / \mathrm{ml}$ penicillin and $100 \mathrm{mg} / \mathrm{ml}$ streptomycin. CT2A murine glioblastoma cells and U87 human glioblastoma cells were cultured in DMEM containing 10\% FBS and $2 \mathrm{mM}$ glutamine (Invitrogen, Life Technologies, Ghent, Belgium) supplemented with conditioned medium obtained from CT2A or U87 cells.

\section{Knock-down and overexpression strategies}

RNA INTERFERENE: CPT1a silencing was achieved using a validated pool of siRNA duplexes directed against human CPT1a (Trifekta Kit, IDT) and lipofectamine RNAi Max transfection reagent (Invitrogen, Belgium) according to the manufacturer's instructions. A scrambled siRNA was used as negative control. LentVIRAL TRANSDUctions: For overexpression of murine CPT1a, the cDNA was cloned in the pRRLsinPPT.CMV.MCS MM W prevector ${ }^{17}$. Of note, this increased FAO in some but not in all EC isolations, suggesting that in such cases CPT1a abundance was not limiting the maximal capacity of FAO. However, whenever FAO was enhanced, sprout numbers and length of EC spheroids were increased. To generate shRNA vectors against CPT1a, CPT1c, or ACADVL, oligonucleotides were cloned into the pLKO-shRNA2 vector (No. PT4052-5; Clontech, Westburg BV, Leusden, the Netherlands) 
(oligonucleotide sequences are available upon request). A nonsense scrambled shRNA sequence was used as a negative control. Production of lentiviruses by transfection into $293 \mathrm{~T}$ cells was performed as described ${ }^{18}$. For transductions, a multiplicity of infection (MOI) of 20 was used in all shCPT1a experiments. For transductions with shACADVL and shCPT1c and for FUCCI and CPT1a overexpression, a MOI of 10 was used. Cells were transduced overnight and re-fed with fresh medium the next day. Transduced cells were used in functional assays at least 3 to 4 days post-transduction. Of note: similar data were obtained using siRNA and 2 non overlapping shRNAs directed against CPT1a.

\section{In vitro assays}

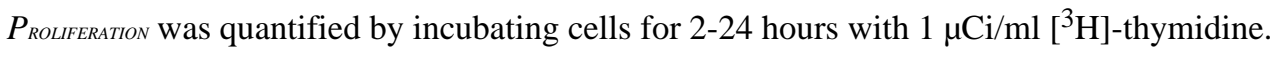
Thereafter, cells were fixed with $100 \%$ ethanol for $15 \mathrm{~min}$ at $4^{\circ} \mathrm{C}$, precipitated with $10 \%$ trichloroacetic acid and lysed with $0.1 \mathrm{~N} \mathrm{NaOH}$. The amount of $\left[{ }^{3} \mathrm{H}\right]$-thymidine incorporated into DNA was measured by scintillation counting. SCRATCH WOUND MIGRATIONASSAY: a scratch wound was applied on confluent EC monolayers (pretreated with MitoC where indicated) using a $200 \mu \mathrm{l}$ tip, 24 hours after seeding (100,000 cells per well in 24-well plates). After scratch wounding and photography (T0), the cultures were further incubated in fully supplemented EBM2 medium for 6-8 hours (until near closure was reached in the control condition), and photographed again (Tx). Migration distance (gap area at T0 minus gap area at Tx) was measured with NIH Image $\mathbf{J}$ software package and is expressed in arbitrary units. MoDIFED BOYDEN CHAMBER MIGRATIONASAAYS were performed using MitoC-treated (24 hour treatment with $2 \mu \mathrm{g} / \mathrm{ml}$ MitoC) ECs. Therefore, 50,000 cells were seeded in fully supplemented EBM2 medium on $0.1 \%$ gelatin coated transwells. Upon adherence, the transwells were washed and refed with medium containing only $0.1 \%$ FBS and transferred to bottom wells containing medium with $0.1 \%$ FBS (baseline) or 5\% FBS (migration stimulus). Transwells were incubated for 16 hours and processed and analyzed for migrated cells as described ${ }^{19}$. LameLIPoDia Formationassar: The number and area of lamellipodia were measured on still photos of time-lapse recordings of sparsely seeded ECs, using the Axiovision morphometric analysis software (Carl Zeiss, Munich, Germany) with in-house developed macros. Lamellipodia area is expressed in percent of total cell area. Directionality of migration was assessed by analysis of the total length of the migration track of a cell. The directionality value was then calculated by dividing the distance between the start and end location of the cell by the total track length; a higher directionality value denotes higher migration directionality. Experiments were performed with or without genetic shRNA CPT1a silencing. S PheroId CAPILARY SPRoUting asSAY: ECs were incubated overnight in hanging drops in EGM-2 medium containing methylcellulose (20 volume $\%$ of a $1.2 \%$ solution of methylcellulose $4000 \mathrm{cP}$ ) (Sigma-Aldrich, Bornem, Belgium) to form spheroids. For mitotic inactivation, MitoC $(2 \mu \mathrm{g} / \mathrm{ml})$ was added to this medium. Spheroids were then embedded in collagen gel as described ${ }^{20}$ and cultured for 20 hours to induce sprouting. Compounds were added at the following concentrations during the collagen gel culture step, using corresponding vehicle concentrations as control: $20 \mathrm{mM}$ sodium acetate, $5 \times$ nucleoside mix, $10 \mathrm{mM}$ NAC, $1.2 \mu \mathrm{M}$ oligomycin, $20 \mu \mathrm{g} / \mathrm{mL}$ cycloheximide, $50 \mu \mathrm{g} / \mathrm{mL} 5 \mathrm{FU}$ or $20 \mu \mathrm{M}$ MTX. Cultures were fixed with 4\% PFA at room temperature and imaged under bright field using a Motic AE 31 microscope (Motic Electric Group Co Ltd., Xiamen, China; or Leica DMI6000 microscope (Leica Microsystems, Mannheim, Germany). Analysis of the number of sprouts 
per spheroid and the total sprout length (cumulative length of primary sprouts and branches per spheroid) was done on phase contrast images using the NIH Image J software package. To assess the number of viable versus dead cells, unfixed spheroids were stained with $500 \mu \mathrm{l}$ of 1/500 dilution of TO-PRO3 (Invitrogen, Life Technologies, Ghent, Belgium) solution at 37 degrees for $10 \mathrm{~min}$, washed with PBS and imaged by confocal microscopy Zeiss LSM 510 Meta NLO or Zeiss LSM 780 confocal microscope (objectives: $\times 10$ with NA $0.3, \times 20$ with NA 0.4) (Carl Zeiss, Munich, Germany) ${ }^{21}$. ATP MEASUREMENT: Analysis of total ATP levels was performed using a commercially available kit (ATPlite ${ }^{\mathrm{TM}}$, PerkinElmer). APOPTOSIs: Analysis of apoptosis was done by fluorescent staining for cleaved caspase 3 (Cell signaling Technology, Bioke, Leiden, the Netherlands) in PFA fixed monolayers.

\section{RNA analysis}

RNA expression analysis was performed by Taqman quantitative RT-PCR as described ${ }^{22}$ using in house-designed primers and probes or premade primer sets (Applied Biosystems, Carlsbad, CA and IDT, Belgium). Sequences or premade primer set ID numbers are available upon request. For comparison of gene expression between conditions, expression (normalized to HPRT endogenous control) is expressed relative to control condition. For comparison between different genes, absolute expression levels were determined based on respective cDNA standard curves, and levels are expressed as copies mRNA $/ 10^{3}$ copies HPRT mRNA.

\section{Immunoblot analysis}

Protein extraction and immunoblot analysis were performed using a modified Laemmli sample buffer (125 mM Tris-HCl, pH 6.8 buffer containing $2 \%$ SDS and $10 \%$ glycerol $)^{22}$ or cell lysis buffer (Cell Signaling Technology) in the presence of protease and phosphatase inhibitors (Roche, Vilvoorde, Belgium). Lysates were separated by SDS-PAGE under reducing conditions, transferred to a nitrocellulose or PVDF membrane, and analyzed by immunoblotting. Primary antibodies used were rabbit anti-CPT1a (No. 12252), rabbit antiLamin A/C (No. 2032), rabbit anti- $\beta$-actin (No. 4970), anti-total AMPKa (No. 2532), rabbit anti-phospho-AMPKa Thr172 (No. 2531), anti-p21 (No. 2947), anti-phospho-ATM (No. 5883), anti-total ATM (No. 2873) (Cell Signaling Technology, Bioké, Leiden, the Netherlands), and anti-total p53 (FL 393, Santa Cruz Biotechnology, the Netherlands). Autophagy was analyzed via western blot determination of LC3 II/I ratio (No. 3868, Cell Signaling Technology) to reveal the on-state of autophagy (autophagic flux). Equal loading was verified by Ponceau Red staining and Lamin A/C or ß-actin as loading controls. Appropriate secondary antibodies were from Dako (Enschede, the Netherlands). Signal was detected using the ECL system (Amersham Biosciences, GE Healthcare, Diegem, Belgium) according to the manufacturer's instructions. Densitometric quantifications of bands were done with NIH Image $\mathbf{J}$ software.

\section{Flow cytometry}

$P_{\text {RoteIN }} / R N A$ sYNTHESIS: Protein synthesis was determined by incubation of cells with a methionine analogue (HPG, Invitrogen) for $24 \mathrm{~h}$ in full medium. RNA synthesis was determined by incubation of cells with a uridine analogue (5'-ethynyl uridine, EU, molecular 
probes). Cells were trypsinized, PFA fixed and incorporated HPG or 5'-ethynyl uridine was detected by a Click-IT reaction with Alexa fluor 647 according to the manufacturer's instructions. Alexa fluor 647 was excited with a $604 \mathrm{~nm}$ red laser and emission was recorded at $660 \mathrm{~nm}$ using a BD FACS Canto flow cytometer (Becton Dickinson Benelux NV,

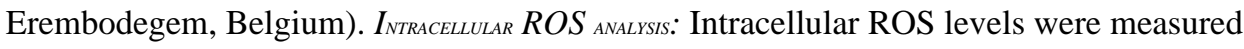
using the CM-DCF dye according to the manufacturer's instructions (Invitrogen, Belgium). For flow cytometry analysis the BD FACS Verse flow cytometer was used. $C_{E L L C O U N T}$ : for assessment of cell number, cells were seeded in a 24-well plate and trypsinized after $48 \mathrm{~h}$ growth. Cells were resuspended in $150 \mu \mathrm{l}$ of PBS and $100 \mu \mathrm{l}$ of cell suspension was counted at a flow rate of $1 \mu \mathrm{l}$ per second. Data were analyzed using FlowJo analysis software.

\section{Metabolism assays}

$F_{\text {ATTY ACID OXIDATION: }}$ ECs were incubated in fully supplemented EBM2 medium with $100 \mu \mathrm{M}$ unlabeled palmitate and $50 \mu \mathrm{M}$ carnitine. Cells were incubated for 2 hours in growth medium containing $2 \mu \mathrm{Ci} / \mathrm{ml}\left[9,10-{ }^{3} \mathrm{H}\right]$-palmitate ${ }^{23,24}$. Thereafter, supernatant was transferred into glass vials sealed with rubber stoppers. ${ }^{3} \mathrm{H}_{2} \mathrm{O}$ was captured in hanging wells containing a Whatman paper soaked with $\mathrm{H}_{2} \mathrm{O}$ over a period of 48 hours at $37^{\circ} \mathrm{C}$ to reach saturation $^{25}$. Radioactivity was determined by liquid scintillation counting. GLYCOLYSIS: Glycolysis was measured analogously to fatty acid oxidation (cf supra) using $80 \mathrm{mCi} / \mathrm{mmol}$ [5- $\left.{ }^{3} \mathrm{H}\right]-\mathrm{D}$-glucose (Perkin Elmer) ${ }^{23} \cdot{ }^{14} \mathrm{C}$-GLUCOSE OxIDATION: Cells were incubated for 6 hours in growth medium containing $100 \mu \mathrm{Ci} / \mathrm{mmol}\left[6-{ }^{14} \mathrm{C}\right]-\mathrm{D}$-glucose. Thereafter, $250 \mu \mathrm{l}$ of $2 \mathrm{M}$ perchloric acid was added to each well to stop cellular metabolism and wells were immediately covered with a $1 \times$ hyamine hydroxide-saturated Whatman paper. Overnight absorption of ${ }^{14} \mathrm{CO}_{2}$ released during oxidation of glucose into the paper was performed at room temperature, and radioactivity in the paper was determined by liquid scintillation counting. ${ }^{14} C$-gLUTAMINE oxidation: was performed similarly as glucose oxidation, except that we used $0.5 \mu \mathrm{Ci} / \mathrm{ml}\left[\mathrm{U}^{14} \mathrm{C}\right]$-glutamine as tracer. $P_{\text {ALMITATE OR HYPOXANTHINE MEDIATED }} R N A_{\text {AND }}$ DNA SYNTHESIS: was measured by the incorporation of ${ }^{14} \mathrm{C}$ into RNA or DNA using $100 \mu \mathrm{Ci} / \mathrm{mmol}\left[\mathrm{U}-{ }^{14} \mathrm{C}\right.$ ]palmitate or $\left[8-{ }^{14} \mathrm{C}\right]$-hypoxanthine and was corrected for the total amount of RNA or DNA per sample. Total RNA and DNA were isolated using commercially available column-based DNA and RNA extraction kits (Qiagen) or using Trizol as an alternative extraction method for RNA or DNA. ATP Coupled oxyGen ConsUmption: Cells were seeded at 40,000 cells per well on Seahorse XF24 tissue culture plates (Seahorse Bioscience Europe, Copenhagen, Denmark). The measurement of oxygen consumption was performed at 10 min intervals ( 2 min mixing, 2 min recovery, 6 min measuring) for 3 hours using the Seahorse XF24 analyzer. For ATP coupled oxygen consumption, measurements were performed before and after oligomycin $(1.2 \mu \mathrm{M})$ treatment. ENERGY BALANCE ASESSSMENT: $1.5 \times 10^{6}$ cells were harvested in ice cold $0.4 \mathrm{M}$ perchloric acid supplemented with $0.5 \mathrm{mM}$ EDTA. $\mathrm{pH}$ was adjusted by adding $100 \mu \mathrm{l}$ of 2 $\mathrm{M} \mathrm{K}_{2} \mathrm{CO} 3.100 \mu \mathrm{l}$ of the mixture was injected onto an Agilent 1260 HPLC equipped with a $\mathrm{C} 18$-Symmetry column $(150 \times 4.6 \mathrm{~mm} ; 5 \mu \mathrm{m})$ (Waters), thermostated at $22.5^{\circ} \mathrm{C}$. Flow rate was kept constant at $1 \mathrm{ml} / \mathrm{min}$. A linear gradient using solvent A $\left(50 \mathrm{mM} \mathrm{NaH}_{2} \mathrm{PO} 4,4 \mathrm{mM}\right.$ tetrabutylammonium, adjusted to $\mathrm{pH} 5.0$ using $\left.\mathrm{H}_{2} \mathrm{SO} 4\right)$ and solvent $\mathrm{B}\left(50 \mathrm{mM} \mathrm{NaH}_{2} \mathrm{PO} 4,4\right.$ $\mathrm{mM}$ tetrabutylammonium, $30 \% \mathrm{CH}_{3} \mathrm{CN}$, adjusted to $\mathrm{pH} 5.0$ using $\mathrm{H}_{2} \mathrm{SO} 4$ ) was accomplished as follows: $95 \%$ A for $2 \mathrm{~min}$, from 2 to 25 min linear increase to $100 \% \mathrm{~B}$, from 25 to $27 \mathrm{~min}$ isocratic at $100 \% \mathrm{~B}$, from 27 to 29 min linear gradient to $95 \% \mathrm{~A}$ and 
finally from 29 to $35 \mathrm{~min}$ at $95 \%$ A. Detection of ATP, ADP and AMP occurred at $259 \mathrm{~nm}$. GSSG/GSH RATIO MEASUREMENT. Samples were collected in $300 \mu 15 \%$ TCA (trichloro-acetic acid, Sigma). $50 \mu \mathrm{l}$ was loaded onto an Ultimate 3000 UPLC (Thermo Scientific, Bremen, Germany) equipped with a Acquity UPLC HSS T3 column (cat \# 186003976; $2.1 \times 5 \mathrm{~mm}$; $1.8 \mu \mathrm{m}$ particles; Waters) in line connected to a $\mathrm{Q}$ Exactive mass spectrometer (Thermo Fisher Scientific). A linear gradient was carried out using solvent A ( $0.05 \%$ formic acid) and solvent B (60\% methanol, $0.05 \%$ formic acid). Practically, samples were loaded at $99 \%$ solvent A and from 10 to $12 \mathrm{~min}$ a ramp to $100 \%$ solvent B was carried out. From 15 to 16 min the column returned to $99 \%$ solvent A and the run was stopped at 21 min. Elution of GSH and GSSG occurred at 3 and 5.5 min respectively (isocratic separation). Flow rate was constant at $250 \mu \mathrm{l} / \mathrm{min}$ and the column temperature was kept constant at $37^{\circ} \mathrm{C}$. The mass spectrometer operated in targeted SIM mode following the ions $\mathrm{m} / \mathrm{z} 311.11456$ and 308.59499 (GSH and GSSG respectively) using the ion 445.12003 as lock mass. The mass spectrometer ran in positive polarity, the source voltage was $3.0 \mathrm{kV}$, and the capillary temperature was set at $350^{\circ} \mathrm{C}$. Additional sheath gas flow was put at 35 and auxiliary gas flow rate at 10 . Auxiliary gas heater temperature was put at $60^{\circ} \mathrm{C}$. AGC target was put at 1e5 ions with a maximum ion injection time of $200 \mathrm{~ms}$ ) acquired at a resolution of 70000 . For the data analyses we manually integrated the peaks representing GSH and GSSG using the Thermo XCalibur Qual Browser software (Thermo Scientific) and data is represented as area of the respective GSH and GSSG peaks. DETERMINATION OF ${ }^{13}{ }^{13}$-PALMITATE, GLUCOSE AND GLUTAMINE INCORPORATION IN METABOLTES AND TOTAL METABOLTE LEVELS: For ${ }^{13} \mathrm{C}$-carbon incorporation from palmitate in metabolites, cells were incubated for 48 hours with labeled substrates (confirmation of steady state at that time was confirmed, see Extended Data Fig. 5). For ECs, [U-13 C]palmitate labeling was done in two ways: (1) "100\% labeling", whereby all cold palmitate in M199 culture medium $(120 \mu \mathrm{M})$ was replaced by $120 \mu \mathrm{M}\left[\mathrm{U}-{ }^{13} \mathrm{C}\right]$-palmitate using M199 medium, containing charcoal stripped serum (which does not contain any fatty acids); and (2) "50/50\% labeling", whereby $100 \mu \mathrm{M}\left[\mathrm{U}_{-}{ }^{13} \mathrm{C}\right]$-palmitate was added to the EGM2 culture medium containing $100 \mu \mathrm{M}$ cold palmitate. Both types of labeling yielded similar data and were thus pooled. For comparison with cancer cells, only the $100 \%$ labeling strategy was used. Similar labeling methods were used for glucose $(5.5 \mathrm{mM})$ and glutamine $(2 \mathrm{mM})$. Labeling with the algal $\left[\mathrm{U}_{-}{ }^{13} \mathrm{C}\right]$ fatty acid mix was performed by using $100 \%$ labeling; this fatty acid mix contained $50 \mu \mathrm{M}$ palmitate. Metabolites for the subsequent mass spectrometry analysis were prepared by quenching the cells in liquid nitrogen followed by a cold two phase methanol-water-chloroform extraction ${ }^{7,26}$. Phase separation was achieved by centrifugation at $4{ }^{\circ} \mathrm{C}$ and the methanol-water phase containing polar metabolites was separated and dried using a vacuum concentrator ${ }^{24,61}$. The dried metabolite samples were stored at $-80^{\circ} \mathrm{C}^{7,26}$. Polar metabolites were derivatized for $90 \mathrm{~min}$ at $37^{\circ} \mathrm{C}$ with $7.5 \mu \mathrm{l}$ of 20 $\mathrm{mg} / \mathrm{ml}$ methoxyamine in pyridine and subsequently for $60 \mathrm{~min}$ at $60^{\circ} \mathrm{C}$ with $15 \mu \mathrm{lof} \mathrm{N}$-(tertbutyldimethylsilyl)-N-methyl-trifluoroacetamide, with $1 \%$ tertbutyldimethylchlorosilane ${ }^{7,26}$. Isotopomer distributions and metabolite levels were measured with a 7890A GC system (Agilent Technologies) combined with a 5975C Inert MS system (Agilent Technologies). One microliter of sample was injected onto a DB35MS column in splitless mode using an inlet temperature of $270{ }^{\circ} \mathrm{C}^{7,26}$. The carrier gas was helium with a flow rate of $1 \mathrm{ml} \mathrm{min}{ }^{-1}$. Upon injection, the $\mathrm{GC}$ oven was held at $100^{\circ} \mathrm{C}$ for 3 min and then ramped to $300{ }^{\circ} \mathrm{C}$ with a gradient of $2.5^{\circ} \mathrm{C} \mathrm{min}^{-1}$. The MS system was 
operated under electron impact ionization at $70 \mathrm{eV}$ and a mass range of 100-650 amu was scanned. Isotopomer distributions were extracted from the raw ion chromatograms using a custom Matlab M-file, which applies consistent integration bounds and baseline correction to each ion ${ }^{27}$. In addition, we corrected for naturally occurring isotopes using the method of Fernandez et $\mathrm{al}^{28}$. For relative metabolite levels, the total ion count was normalized to the internal standards norvaline and glutarate and to the protein content ${ }^{7,26}$. To correct for enrichment dilution, we used previously reported methods ${ }^{7,29}$, i.e. we divided the fractional contribution of a labeled metabolite of interest by the fractional contribution of its precursor (calculated by the formula below).

The total contribution of carbon was calculated using the following equation ${ }^{7,29}$ :

Total contribution of carbon $=\sum_{i=0}^{n} i * m_{i} /\left(n * \sum_{i=0}^{n} m_{i}\right)$

Herewith, " $n$ " is the number of $\mathrm{C}$ atoms in the metabolite, " $\mathrm{i}$ " represents the different mass isotopomers and " $\mathrm{m}$ " refers to the abundance of a certain mass. Glycolytic carbon contribution was calculated based on $\left[\mathrm{U}_{-}{ }^{13} \mathrm{C}\right]$-glucose labeling and label dilution in pyruvate $^{7}$. For total metabolite levels, arbitrary units of the metabolite of interest were normalized to the protein content. A time-course experiment of the incorporation of $\left[\mathrm{U}_{-}{ }^{13} \mathrm{C}\right]$-glucose, $\left[\mathrm{U}_{-}{ }^{13} \mathrm{C}\right]$-glutamine and $\left[\mathrm{U}_{-}{ }^{13} \mathrm{C}\right]$-palmitate in TCA intermediates demonstrated that the incorporation values reached a pseudo-isotopic steady state within experimental measurement precision (Extended Data Fig. 5). DETERMINATION OF DNTP LEVELSBY $R T$ PCR: dNTP levels were determined by using a fluorescence-based PCR assay ${ }^{30}$ using G1 sorted ECs, identified as CherryRed ${ }^{+}$Venus $^{-}$cells upon transduction with a FUCCI construct ${ }^{31}$. D ETERMINATION OF ${ }^{13} C_{\text {-PALMITATE OR }}{ }^{13}{ }^{1}$-acetate INCORPoration IN UMP AND UTP: Cells were labeled with [U- $\left.{ }^{13} \mathrm{C}\right]$-palmitate (100\% labeling with $100 \mu \mathrm{M}\left[\mathrm{U}_{-}{ }^{13} \mathrm{C}\right]$-palmitate; see above) or $\left[\mathrm{U}_{-}{ }^{13} \mathrm{C}\right]$-acetate $\left(20 \mathrm{mM}\right.$ supplementation with $\left[\mathrm{U}_{-}{ }^{13} \mathrm{C}\right]$-acetate) for 48 hours and were then collected in $500 \mu \mathrm{l}$ ice cold acetonitrile buffer (50\% methanol, 30\% acetonitrile and $20 \%$ water). Samples were spun for $5 \mathrm{~min}$ and supernatants were dried down and were then reconstituted in $50 \mu \mathrm{l}$ of HPLC-grade water, vortexed, centrifuged, and transferred into HPLC vials. LC-MS/MS analysis was done on a Waters Xevo TQ-S mass spectrometry was coupled to an H-Class UPLC system. Metabolites were separated by polarity using Supelco Ascentis Express C18 column $(2.7 \mu \mathrm{m}$ particle size, $5 \mathrm{~cm} \times 2.1 \mathrm{~mm})$. LC parameters are as follows: autosampler temperature, $5^{\circ} \mathrm{C}$; injection volume, $5 \mu \mathrm{l}$; column temperature, $50{ }^{\circ} \mathrm{C}$; flow rate over $11 \mathrm{~min}: \mathrm{t}=0,0.4 \mathrm{ml} / \mathrm{min} ; \mathrm{t}=2,0.3 \mathrm{ml} / \mathrm{min} ; \mathrm{t}=3,0.25 \mathrm{ml} / \mathrm{min} ; \mathrm{t}=5,0.15 \mathrm{ml} /$ $\min ; \mathrm{t}=9,0.4 \mathrm{ml} / \mathrm{min} ; \mathrm{t}=11,0.4 \mathrm{ml} / \mathrm{min}$. The LC solvents were Solvent A: $10 \mathrm{mM}$ tributylamine and $15 \mathrm{mM}$ acetic acid in 97:3 water:methanol (pH 4.95); and Solvent B: methanol. Elution from the column was performed over $11 \mathrm{~min}$ with the following gradient: $\mathrm{t}=0,0 \% \mathrm{~B} ; \mathrm{t}=1,0 \% \mathrm{~B} ; \mathrm{t}=2,20 \% \mathrm{~B} ; \mathrm{t}=3,20 \% \mathrm{~B} ; \mathrm{t}=5,55 \% \mathrm{~B} ; \mathrm{t}=8,95 \% \mathrm{~B} ; \mathrm{t}=8.5$, $95 \% \mathrm{~B}, \mathrm{t}=9,0 \% \mathrm{~B} ; \mathrm{t}=11,0 \% \mathrm{~B}$. Mass spectra were acquired using negative-mode electrospray ionization operating in multiple reaction monitoring (MRM) mode. The capillary voltage was $3000 \mathrm{~V}$, and cone voltage was $50 \mathrm{~V}$. Nitrogen was used as cone gas and desolvation gas, with flow rates of $150 \mathrm{l} / \mathrm{h}$ and $600 \mathrm{l} / \mathrm{h}$, respectively. The source temperature was $150{ }^{\circ} \mathrm{C}$, and desolvation temperature was $500{ }^{\circ} \mathrm{C}$. Argon was used as collision gas at a manifold pressure of $4.3 \times 10^{-3}$ mbar. Collision energies and source cone 
potentials were optimized for each transition using Waters QuanOptimize software. Data were acquired and analyzed using MassLynx 4.1 and QuanLynx software. Isotope labeling data was corrected for the natural abundance of different isotopes using IsoCor ${ }^{32}$. DETERMINATION ${ }_{O F} R N T P P_{L E V E L S B} L C-M S$ : rNTP extracted with the same method as described for UTP and UMP. Additionally, ${ }^{13} \mathrm{C}$-internal standard (generated by based on fully labeled yeast extracts ${ }^{33}$ ) were spiked into the extraction solution. rNTP concentrations were determined with the same LC-MS method as described for UTP and UMP. All samples were normalized to the ${ }^{13} \mathrm{C}$-internal standard and protein content.

\section{Mouse models of ocular angiogenesis}

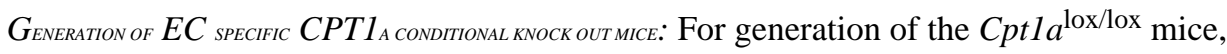
loxP sites were introduced flanking a segment comprising exon 11 and 12 via homologous recombination in embryonic stem (ES) cells. The targeting vector contained from $5^{\prime}$ to $3^{\prime}$ : a $3.5 \mathrm{~kb} 5^{\prime}$ homology flank, a $2 \mathrm{~kb}$ floxed mid flank consisting of the loxP flanked exon 11-12 segment, a FRT flanked neomycine resistance (NEO) cassette, a $2.5 \mathrm{~kb} \mathrm{3}$ ' homology flank. Correctly targeted ES clones were identified by appropriate Southern blot and PCR analysis, and subjected to transient transfection with a Flp recombinase expression plasmid to remove the FRT flanked NEO cassette. Correctly excised clones were used for morula aggregation, and resulting chimeric animals were bred for germline transmission, yielding $C p t 1 a^{\text {wt/lox }}$ and eventually $C p t 1 a^{l o x} / l o x$ mice. For postnatal EC-specific loss of function studies, $V E$ Cadherin(PAC)-Cre ${ }^{E R T 2}$ mice $^{34}$ (provided by R. Adams) were intercrossed with $C p t 1 a^{\text {lox/lox }}$ mice and named CPT1 ${ }_{\mathrm{A}}{ }^{\Delta \mathrm{EC}}$. Correct Cre-mediated excision of the floxed Cpt1a segment in tamoxifen-treated $C P T 1_{\mathrm{A}} \mathrm{\triangle EC}$ mice was confirmed via PCR analysis of genomic DNA using primers spanning the floxed region, by the appearance of a 300-bp band (Extended Data Fig. 1u). CPT1 $1_{\mathrm{A}} \triangle \mathrm{EC}$ mice were always compared with tamoxifen-treated $\mathrm{Cre}^{-}$Cptla $a^{\text {lox/lox }}$ littermates (denoted as WT). AnalysIS OF POSTNATAL RETINAL ANGIOGENESIS: Genetic endothelial cell specific inactivation of CPT1a in neonatal mice was achieved by intraperitoneal injection of $100 \mathrm{mg} / \mathrm{kg}$ Tamoxifen solution (Sigma T5648; dissolved in 1:10 EtOH:corn oil) once daily from postnatal day (P) 1 to $\mathrm{P} 4$ in $\mathrm{CPT} 1 \mathrm{a}^{\Delta \mathrm{EC}}$ mice. Pharmacological blockade of FAO in neonatal C57BL/6 wild type mice (animal facility KULeuven) was achieved by treatment with $30-35 \mathrm{mg} / \mathrm{kg}$ etomoxir from P2 to P4. For detection of cell proliferation, EdU (Invitrogen) was injected 2 hours before dissection. At P5, pups were killed and eyes were enucleated, fixed with $4 \%$ PFA for $2 \mathrm{~h}$ at $4{ }^{\circ} \mathrm{C}$ and prepared for vascular analysis. As all animal treatments were done in baseline conditions, no randomization was required. Retinal whole mounts were prepared for vascular analysis as described ${ }^{4}$. Only litters for which the WT littermates (for $\mathrm{CPT} 1_{\mathrm{A}} \triangle \mathrm{EC}$ mice) or vehicle treated littermates (for etomoxir treated mice) reached normal outgrowth and body weight at P5 were included for analysis. Radial vascular area, branching points, and number of filopodia were analyzed on isolectin GS-IB4 stained retinas (see below) using the NIH Image J software package and Leica LASAF-MMAF morphometric analysis software (MetaMorph) (Leica Microsystems, Mannheim, Germany) with in-house developed macros. No statistical

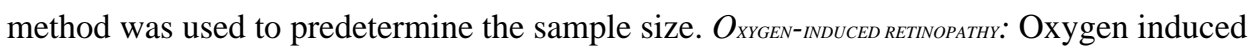
retinopathy (ROP) was induced by exposing C57BL/6 pups with their mother to $70 \%$ oxygen from P7-P12 ${ }^{35}$. Pups were then returned to normoxia and injected daily with 30 $\mathrm{mg} / \mathrm{kg}$ etomoxir or vehicle. At P17, pups were euthanized and eyes were enucleated, fixed in 
4\% PFA and retinal flatmounts were stained for isolectin B4, using previously published methods ${ }^{4}$. Mosaic images were captured using the inverted Leica DMI6000B epifluorescence microscope (Leica, Manheim, Germany) and analysis of the vascular tuft area was performed using NIH Image $\mathbf{J}$ software. For all mouse experiments, data analysis was done by experimentators blinded to the group allocation. All experimental animal procedures were approved by the Institutional Animal Care and Research Advisory Committee of the University of Leuven.

\section{Immunohistochemistry}

PFA fixed cell cultures (4\% PFA except for CPT1a staining where 2\% PFA was used), spheroids (4\% PFA) or whole mount retinas (4\% PFA) were subjected to immunofluorescence staining using the following isolectin conjugates or primary antibodies: isolectin GS-IB4-Alexa 488, isolectin GS-IB4-Alexa 568, isolectin GS-IB4-Alexa 647 (Molecular Probes), anti-CPT1a (Cell Signaling), anti-NG2 Chondroitin Sulfate Proteoglycan (Chemicon), anti-Tomm20 (Abcam) and anti-collagen IV (Southern Biotech). Alexa-488, -568 or -633 conjugated secondary antibodies were used (Molecular Probes). EdU, EU and HPG staining was performed using a Click-IT assay with Alexa fluor 555 according to manufacturer's instructions.

\section{Statistics}

Data represent mean \pm s.e.m. of pooled experiments unless otherwise stated. $\mathrm{N}$ values represent the number of independent experiments performed or the number of individual mice phenotyped. For each independent in vitro experiment, at least 3 technical replicates were used, except for the $\left[\mathrm{U}-{ }^{13} \mathrm{C}\right]$-palmitate incorporation analysis in cell lines (at least 2 technical replicates) (Fig. 6a). Statistical significance between groups was calculated using mixed model statistics (this test does not assume normality or equal variance) with experiment as random factor to correct for variation between umbilical donors (ECs were isolated from human umbilical cords) or mouse litters. SAS statistical software version 9.3 was used for statistical analysis. For comparison of ECs with other cell types, a one-sample $t$-test was used. Sample size for each experiment was not pre-determined. A p-value $<0.05$ was considered statistically significant. 


\section{Extended Data}
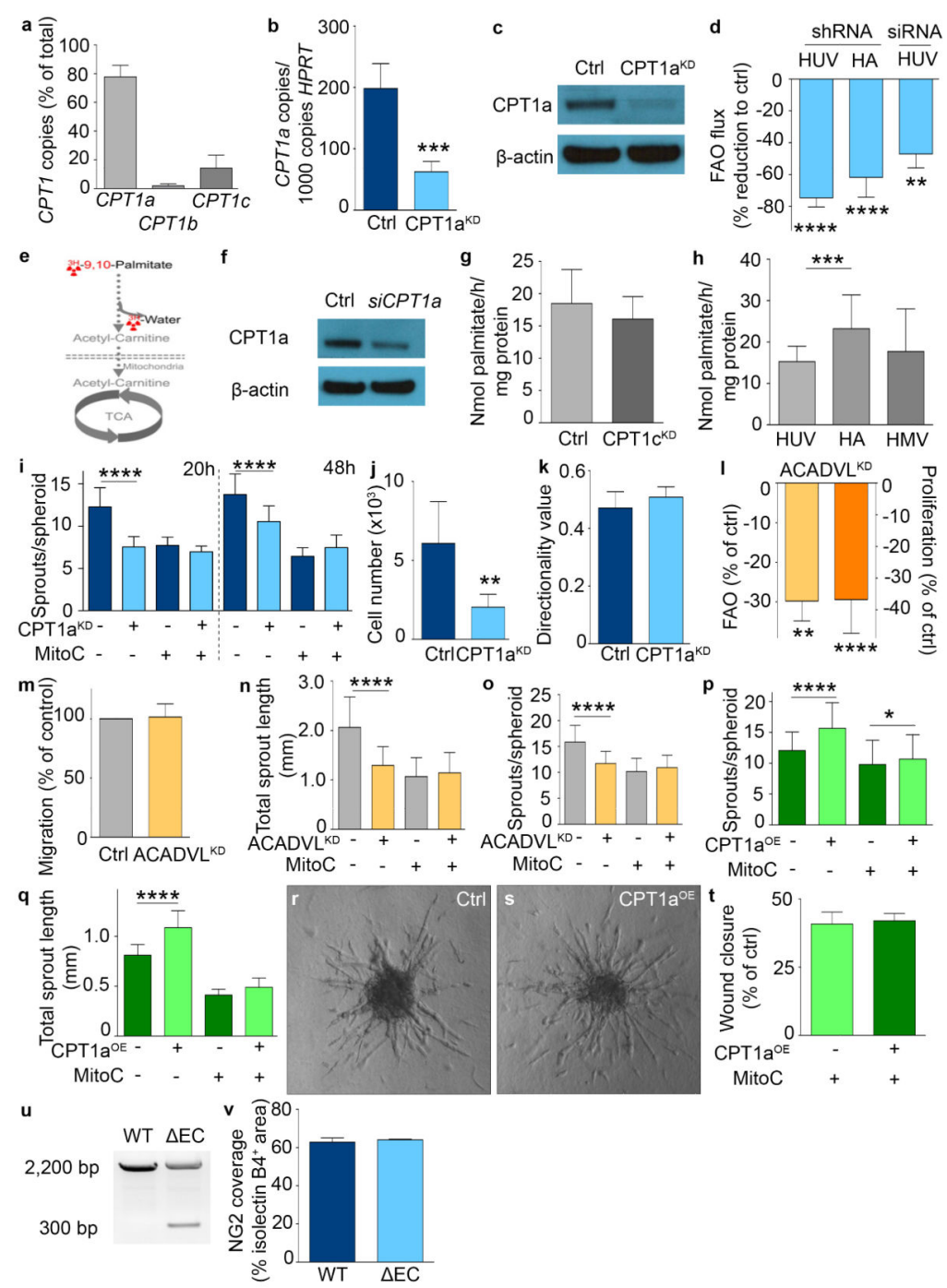

\section{Extended Data Figure 1. FAO regulates vessel sprouting}

a, mRNA expression of CPT1 isoforms (n=3). b, CPTIa mRNA levels upon CPTIa silencing $\left(\mathrm{CPT} 1 \mathrm{a}^{\mathrm{KD}}\right)(\mathrm{n}=11)$. c, Representative immunoblot of CPT1a for control and CPT1 ${ }^{\mathrm{KD}}$ ECs. d, FAO flux upon CPT1a silencing in venous (HUV) and arterial (HA) ECs, or upon small interference RNA transfection in venous ECs (siRNA) ( $n=6$ for HUV shRNA, $\mathrm{n}=3$ for HA shRNA and HUV siRNA). e, Schematic representation of FAO measurement using $\left[9,10-{ }^{3} \mathrm{H}\right]$-palmitate (reproduced from Wang et al. with permission ${ }^{24}$ ). $\mathbf{f}$, Representative immunoblot for CPT1a upon genetic silencing of CPTla using siRNA (siCPTla). g, FAO flux upon silencing of CPT1c $\left(\mathrm{CPT} 1 \mathrm{c}^{\mathrm{KD}}\right)(\mathrm{n}=3$ independent $\mathrm{p}=\mathrm{NS}) . \mathbf{h}$, FAO flux levels in venous (HUV), arterial (HA) and microvascular (HMV) ECs ( $\mathrm{n}=4$ for HUV vs HA and $n=3$ for HUV vs HMV). $\mathbf{i}$, Sprout number in control and CPT1 ${ }^{\mathrm{KD}} \mathrm{EC}$ spheroids with mitomycin $\mathrm{C}$ (MitoC) treatment as indicated $(n=3) \mathbf{j}$, Flow cytometry counting of viable control and CPT1 ${ }^{\mathrm{KD}} \mathrm{ECs}(\mathrm{n}=3)$. $\mathbf{k}$, Analysis of random cell-motility tracks in control and CPT1 $\mathrm{a}^{\mathrm{KD}} \mathrm{ECs}(\mathrm{n}=4 ; \mathrm{p}=\mathrm{NS}) . \mathrm{l}, \mathrm{FAO}$ flux and proliferation upon 
silencing of ACADVL (ACADVL $\left.{ }^{\mathrm{KD}}\right)$ ( $\mathrm{n}=3$ for each). $\mathbf{m}$, Wound closure in control and $\operatorname{ACADVL}^{\mathrm{KD}} \mathrm{ECs}(\mathrm{n}=3 ; \mathrm{p}=\mathrm{NS})$. n,o, Quantification of vessel sprouting in control and ACADVL ${ }^{\mathrm{KD}}$ EC spheroids with MitoC treatment as indicated, total sprout length (n) and sprout numbers per spheroid (o) $(n=5)$. p, Sprout number in control and CPT1 $\mathrm{a}^{\mathrm{OE}} \mathrm{EC}$ spheroids with MitoC treatment as indicated $(\mathrm{n}=3)$. q, Total sprout length in control and $\mathrm{CPT} 1 \mathrm{a}^{\mathrm{OE}} \mathrm{EC}$ spheroids treated with MitoC as indicated $(\mathrm{n}=5)$. $\mathbf{r}, \mathbf{s}$, Representative phase contrast images of control (r) and CPT1a $\mathrm{a}^{\mathrm{OE}}$ (s) EC spheroids. $\mathbf{t}$, Scratch wound assay in control and $\mathrm{CPT} 1 \mathrm{a}^{\mathrm{OE}}$ ECs treated with MitoC as indicated $(\mathrm{n}=3 ; \mathrm{p}=\mathrm{NS})$. $\mathbf{u}, \mathrm{PCR}$ analysis of genomic DNA from WT and CPT1 $\mathrm{a}^{\Delta \mathrm{EC}}$ pups, confirming Cre-mediated recombination of the floxed Cptla allele as shown by the appearance of a $300 \mathrm{bp}$ band. $\mathbf{v}, \mathrm{NG}^{+}$area in neonatal vascular plexus of WT and CPT1 $\mathrm{a}^{\Delta \mathrm{EC}}$ mice ( 3 litters, $\mathrm{n}=8$ pups for WT and 7 pups for $\left.\mathrm{CPT} 1 \mathrm{a}^{\triangle \mathrm{EC}} ; \mathrm{p}=\mathrm{NS}\right)$. Data are mean \pm s.e.m of $\mathrm{n}$ independent experiments $(\mathrm{a}, \mathrm{b}, \mathrm{d}, \mathrm{g}-\mathrm{q}, \mathrm{t})$ or the total number of mice (v). Statistical test: mixed models. NS, not significant. *p<0.05, $* * \mathrm{p}<0.01, * * * \mathrm{p}<0.001, * * * * \mathrm{p}<0.0001$
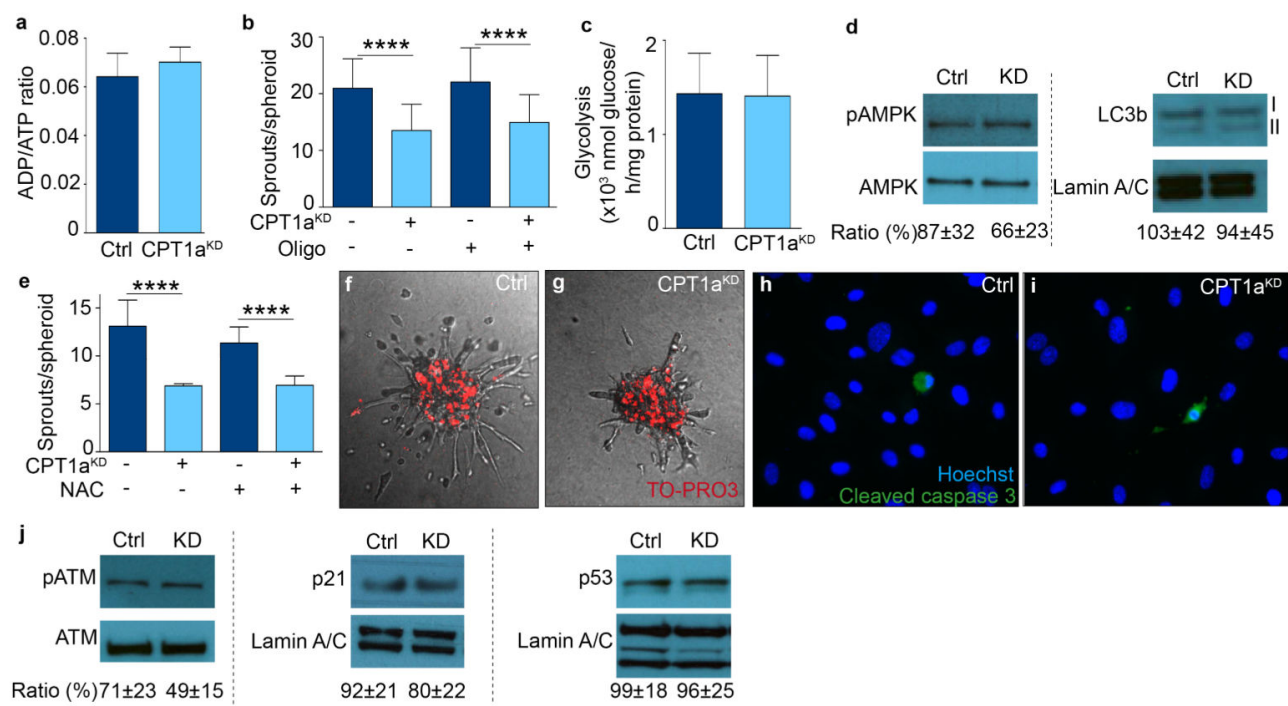

Extended data Figure 2. CPT1a silencing does not cause cellular distress a, ADP/ATP ratio in control and CPT1 ${ }^{\mathrm{KD}}$ ECs $(n=3 ; p=N S)$. b, Sprout number upon oligomycin treatment (oligo) in control and $\mathrm{CPT} 1 \mathrm{a}^{\mathrm{KD}} \mathrm{EC}$ spheroids $(\mathrm{n}=3)$. c, Glycolysis measurement in control and CPT1 $\mathrm{a}^{\mathrm{KD}}$ ECs $(\mathrm{n}=3 ; \mathrm{p}=\mathrm{NS})$. $\mathbf{d}$, Representative immunoblot for phosphorylated AMPK (pAMPK) and total AMPK (AMPK) and for LC3b I and II in control and CPT $1 \mathrm{a}^{\mathrm{KD}}$ ECs. The ratio of the densitometrically quantified bands of pAMPK/ AMPK and LC $3 b$ II/I is shown below the blots $(n=3 ; p=N S)$. e, Sprout number upon Nacetylcysteine (NAC) treatment in control and $\mathrm{CPT}^{\mathrm{K}}{ }^{\mathrm{KD}} \mathrm{EC}$ spheroids $(\mathrm{n}=3) . \mathbf{f}, \mathbf{g}$, Representative images of EC spheroids upon staining for TO-PRO3 in control (f) and CPT1 $\mathrm{a}^{\mathrm{KD}}$ spheroids (g). h,i, Representative pictures of Hoechst/cleaved caspase 3-stained control (h) and CPT1 $\mathrm{a}^{\mathrm{KD}}$ (i) ECs. $\mathbf{j}$, Representative immunoblots, showing the ratio of phosphorylated (pATM) / total-ATM (ATM), p21 / Lamin and p53 / Lamin in control and $\mathrm{CPT} 1 \mathrm{a}^{\mathrm{KD}} \mathrm{ECs}$. The ratios of the densitometrically quantified bands are shown below the blots $(n=3 ; p=N S)$. Data are mean \pm s.e.m of $n$ independent experiments (a-e,j). Statistical test: mixed models. NS, not significant. $* * *$ p $<0.0001$. 

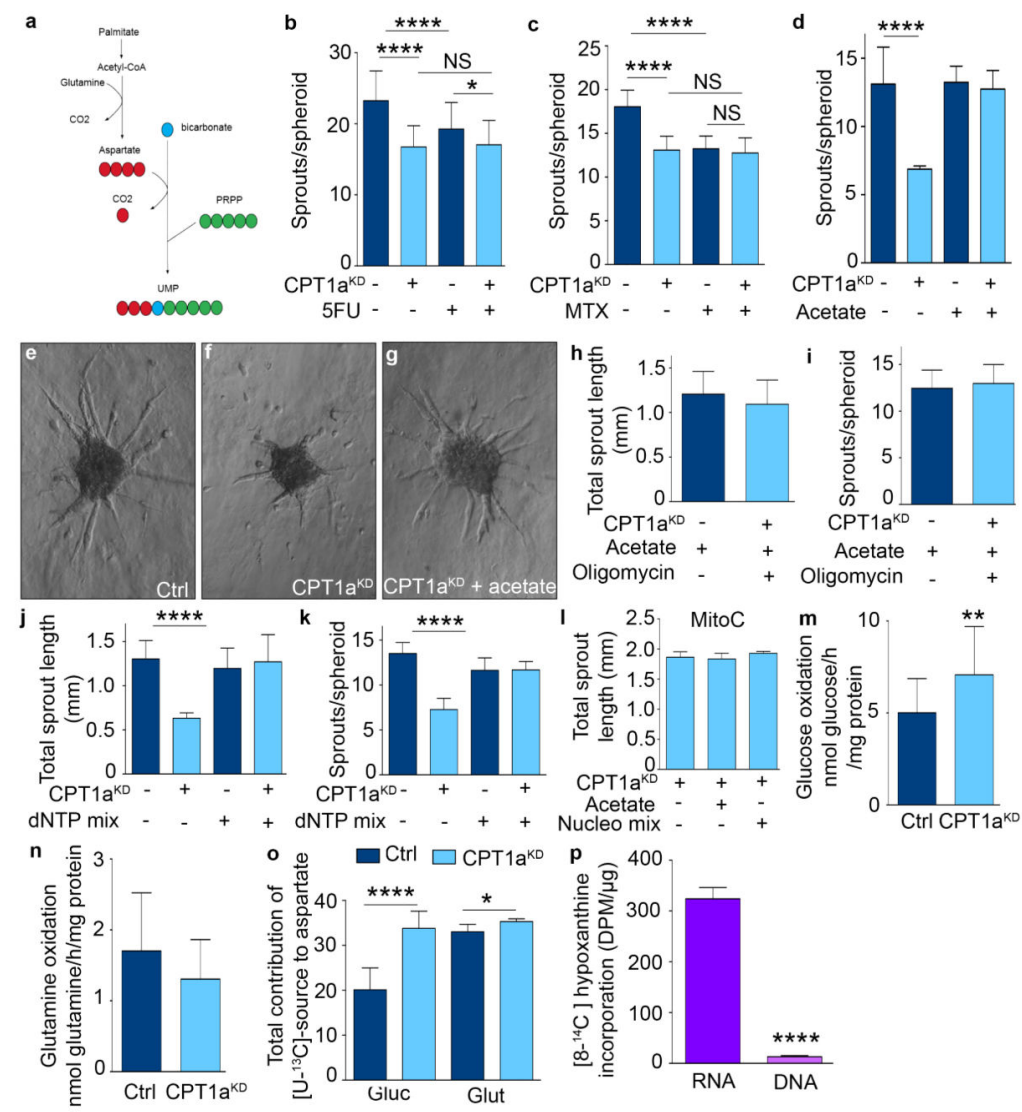

Extended data Figure 3. FAO is used for de novo nucleotide synthesis

a, Schematic representation of the different carbon sources used for de novo synthesis of UMP. Note that palmitate contributes 3 carbons to the 9 carbons skeleton of UMP. PRPP: 5phosphoribosyl-1-pyrophosphate. b, Sprout number upon 5-fluorouracil (5FU) treatment in control and CPT1 $\mathrm{a}^{\mathrm{KD}}$ EC spheroids $(\mathrm{n}=4)$. c, Sprout number upon methotrexate (MTX) treatment in control and $\mathrm{CPT} 1 \mathrm{a}^{\mathrm{KD}} \mathrm{EC}$ spheroids $(\mathrm{n}=4)$. d, Sprout number upon acetate treatment in control and $\mathrm{CPT}_{1} \mathrm{a}^{\mathrm{KD}} \mathrm{EC}$ spheroids $(\mathrm{n}=3)$. e-g, Representative images of $\mathrm{EC}$ spheroids upon acetate treatment. h,i, Rescue of the sprouting defect of $\mathrm{CPT} 1 \mathrm{a}^{\mathrm{KD}}$ spheroids by acetate was not affected by oligomycin treatment; panel h: total sprout length; panel i: sprout numbers/spheroid $(n=3 ; p=N S)$. $\mathbf{j}, \mathbf{k}$, Quantification of vessel sprouting using the EC spheroid model, showing that the reduction of total sprout length $(j)$ and number of sprouts per spheroid $(\mathrm{k})$ upon CPT1a silencing $\left(\mathrm{CPT} 1 \mathrm{a}^{\mathrm{KD}}\right)$ was rescued by supplementation with a dNTP mix $(n=3)$. l, Quantification of MitoC treated EC spheroid sprouting upon acetate or nucleoside mix supplementation ( $\mathrm{n}=3 ; \mathrm{p}=\mathrm{NS}$ ). $\mathbf{m}$, Glucose oxidation in ECs, measured by ${ }^{14} \mathrm{CO}_{2}$ formation from $\left[6-{ }^{14} \mathrm{C}\right]$-glucose in control and $\mathrm{CPT} 1 \mathrm{a}^{\mathrm{KD}} \mathrm{ECs}(\mathrm{n}=4)$. $\mathbf{n}$, Glutamine oxidation in ECs, measured by ${ }^{14} \mathrm{CO}_{2}$ formation from [U- $\left.{ }^{14} \mathrm{C}\right]$-glutamine in control and $\mathrm{CPT} 1 \mathrm{a}^{\mathrm{KD}} \mathrm{ECs}(\mathrm{n}=4 ; \mathrm{p}=\mathrm{NS})$. $\mathbf{o}$, Total contribution of $\left[\mathrm{U}-{ }^{13} \mathrm{C}\right]$-glucose and $\left[\mathrm{U}-{ }^{13} \mathrm{C}\right]-$ glutamine to aspartate in control and CPT1 $\mathrm{a}^{\mathrm{KD}} \mathrm{ECs}(\mathrm{n}=3)$. p, $\left[8-{ }^{14} \mathrm{C}\right]$ hypoxanthine incorporation in RNA and DNA in control ECs $(n=3)$. Data are mean \pm s.e.m of $n$ independent experiments (b-d,h-p). Statistical test: mixed models. NS, not significant. $* \mathrm{p}<0.05, * * \mathrm{p}<0.01, * * * * \mathrm{p}<0.0001$. 

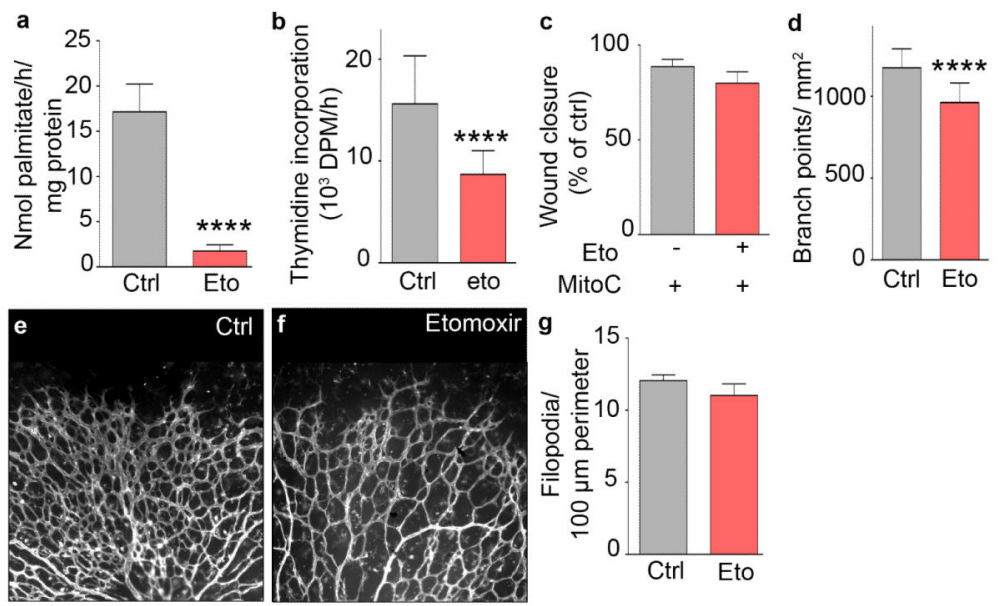

Extended data Figure 4. Etomoxir reduces vessel sprouting

a, FAO flux upon etomoxir (eto) treatment $(\mathrm{n}=6) . \mathbf{b},\left[{ }^{3} \mathrm{H}\right]$-thymidine incorporation upon etomoxir treatment $(n=5)$. $\mathbf{c}$, Scratch wound assay using MitoC-treated ECs upon etomoxir (eto) treatment $(n=4 ; p=N S)$. d, Branch point quantification in the retinal vasculature of control (ctrl) and etomoxir-treated (eto) pups ( 8 litter, $n=24$ pups for control and 16 for etomoxir treatment). e,f, Representative confocal images of retinal vessels stained for isolectin-B4 in control (e) and etomoxir (f) treated pups. g, Filopodia quantification in the retinal vasculature front of control and etomoxir (eto) treated pups ( 4 litters, $n=11$ for WT and 9 for etomoxir; $\mathrm{p}=\mathrm{NS})$. Data are mean \pm s.e.m of $\mathrm{n}$ independent experiments $(\mathrm{a}-\mathrm{d}, \mathrm{g})$ or the total number of mice $(\mathrm{d}, \mathrm{g})$. Statistical test: mixed models. NS, not significant. $* * * * \mathrm{p}<0.0001$.
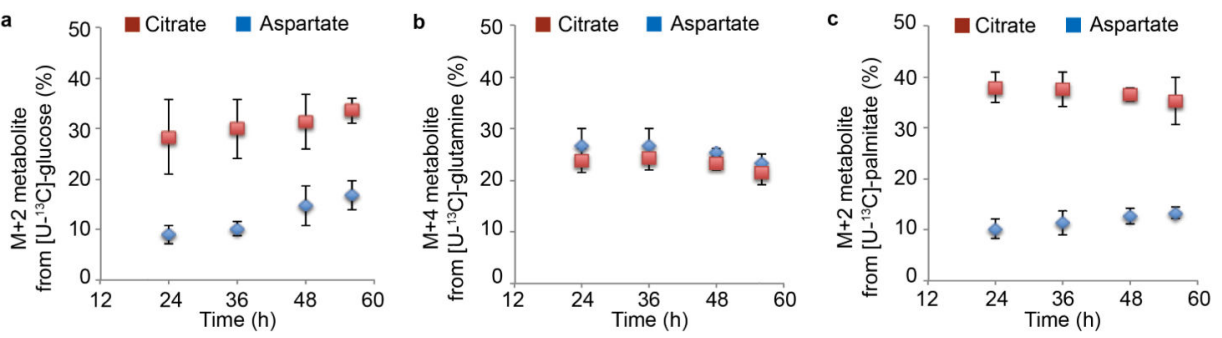

Extended data Figure 5. Analysis of steady state

Percentage M+2 or M+4 citrate and aspartate over different timepoints (24, 36, 48 and 52 hours) after labeling with $\left[\mathrm{U}_{-}{ }^{13} \mathrm{C}\right]$-glucose $(\mathrm{a}),\left[\mathrm{U}-{ }^{13} \mathrm{C}\right]$-glutamine $(\mathrm{b})$, or $\left[\mathrm{U}_{-}{ }^{13} \mathrm{C}\right]$-palmitate (c). Data are mean \pm s.d. of $n=3$ independent experiments.

\section{Acknowledgements}

We thank Matthew Vander Heiden and David Tollervey for discussion, Ralf Adams for providing VECadherin(PAC)-CreERT2 mice, and Sonsoles Rodríguez-Arístegui for synthesis of etomoxir. SS is funded by the Institution of Research / Innovation (IWT); RM, BG, ARC and JG by the Research Foundation Flanders (FWO); UB by a Marie Curie-IEF Fellowship; KCSQ by CAPES (Brasil) and GB by KU Leuven. The work of SMF is supported by Marie Curie CIG, FWO-OdysseusII, Concern Foundation, Bayer Healthcare Pharmaceuticals. The work of PC is supported by IUAP7/03, Methusalem funding (Flemish Government), FWO grants, Foundation Leducq Transatlantic Network (ARTEMIS), Foundation against Cancer, European Research Council (ERC) Advanced Research Grant (EU-ERC269073) and AXA Research grant. SYL was supported by the Department of 
Defense CDMRP Visionary Postdoctoral Award (W81XWH-12-1-0466). Views and opinions of, and endorsements by the authors do not reflect those of the US Army or the Department of Defense. The authors thank the MSU LCMS Core.

\section{References}

1. Potente M, Gerhardt H, Carmeliet P. Basic and therapeutic aspects of angiogenesis. Cell. 2011; 146:873-887. [PubMed: 21925313]

2. Ausprunk DH, Folkman J. Migration and proliferation of endothelial cells in preformed and newly formed blood vessels during tumor angiogenesis. Microvasc Res. 1977; 14:53-65. [PubMed: 895546]

3. Welti J, Loges S, Dimmeler S, Carmeliet P. Recent molecular discoveries in angiogenesis and antiangiogenic therapies in cancer. J Clin Invest. 2013; 123:3190-3200. [PubMed: 23908119]

4. De Bock K, et al. Role of PFKFB3-Driven Glycolysis in Vessel Sprouting. Cell. 2013; 154:651663. [PubMed: 23911327]

5. De Bock K, Georgiadou M, Carmeliet P. Role of endothelial cell metabolism in vessel sprouting. Cell Metab. 2013; 18:634-647. [PubMed: 23973331]

6. Colavitti R, et al. Reactive oxygen species as downstream mediators of angiogenic signaling by vascular endothelial growth factor receptor-2/KDR. J Biol Chem. 2002; 277:3101-3108. [PubMed: 11719508]

7. Fendt SM, et al. Reductive glutamine metabolism is a function of the alpha-ketoglutarate to citrate ratio in cells. Nat Commun. 2013; 4:2236. [PubMed: 23900562]

8. Vander Heiden MG. Exploiting tumor metabolism: challenges for clinical translation. J Clin Invest. 2013; 123:3648-3651. [PubMed: 23999437]

9. Thompson CB. Wnt meets Warburg: another piece in the puzzle? EMBO J. 2014; 33:1420-1422. [PubMed: 24843042]

10. Carracedo A, Cantley LC, Pandolfi PP. Cancer metabolism: fatty acid oxidation in the limelight. Nat Rev Cancer. 2013; 13:227-232. [PubMed: 23446547]

11. Henry TD, Satran D, Jolicoeur EM. Treatment of refractory angina in patients not suitable for revascularization. Nat Rev Cardiol. 2014; 11:78-95. [PubMed: 24366073]

12. Morris GW, Iams TA, Slepchenko KG, McKee EE. Origin of pyrimidine deoxyribonucleotide pools in perfused rat heart: implications for $3^{\prime}$-azido-3'-deoxythymidine-dependent cardiotoxicity. Biochem J. 2009; 422:513-520. [PubMed: 19558366]

13. Fairbanks LD, Bofill M, Ruckemann K, Simmonds HA. Importance of ribonucleotide availability to proliferating T-lymphocytes from healthy humans. Disproportionate expansion of pyrimidine pools and contrasting effects of de novo synthesis inhibitors. J Biol Chem. 1995; 270:2968229689. [PubMed: 8530356]

14. Lunt SY, et al. Pyruvate kinase isoform expression alters nucleotide synthesis to impact cell proliferation. Mol Cell. 2015; 57:95-107. [PubMed: 25482511]

\section{References unique to the Methods section}

15. Cheung EC, et al. TIGAR is required for efficient intestinal regeneration and tumorigenesis. Dev Cell. 2013; 25:463-477. [PubMed: 23726973]

16. Jaffe EA, Nachman RL, Becker CG, Minick CR. Culture of human endothelial cells derived from umbilical veins. Identification by morphologic and immunologic criteria. J Clin Invest. 1973; 52:2745-2756. [PubMed: 4355998]

17. Michieli $\mathrm{P}$, et al. Targeting the tumor and its microenvironment by a dual-function decoy Met receptor. Cancer cell. 2004; 6:61-73. [PubMed: 15261142]

18. Carlotti F, et al. Lentiviral vectors efficiently transduce quiescent mature 3T3-L1 adipocytes. Mol Ther. 2004; 9:209-217. [PubMed: 14759805]

19. Geudens I, et al. Role of delta-like-4/Notch in the formation and wiring of the lymphatic network in zebrafish. Arterioscler Thromb Vasc Biol. 2010; 30:1695-1702. [PubMed: 20466977]

Nature. Author manuscript; available in PMC 2015 October 09. 
20. Korff T, Krauss T, Augustin HG. Three-dimensional spheroidal culture of cytotrophoblast cells mimics the phenotype and differentiation of cytotrophoblasts from normal and preeclamptic pregnancies. Exp Cell Res. 2004; 297:415-423. [PubMed: 15212944]

21. Schoors S, et al. Partial and Transient Reduction of Glycolysis by PFKFB3 Blockade Reduces Pathological Angiogenesis. Cell Metab. 2014; 19:37-48. [PubMed: 24332967]

22. Carmeliet $P$, et al. Synergism between vascular endothelial growth factor and placental growth factor contributes to angiogenesis and plasma extravasation in pathological conditions. Nat Med. 2001; 7:575-583. [PubMed: 11329059]

23. Dagher Z, Ruderman N, Tornheim K, Ido Y. Acute regulation of fatty acid oxidation and ampactivated protein kinase in human umbilical vein endothelial cells. Circ Res. 2001; 88:1276-1282. [PubMed: 11420304]

24. Wang R, et al. The transcription factor Myc controls metabolic reprogramming upon T lymphocyte activation. Immunity. 2011; 35:871-882. [PubMed: 22195744]

25. Aragones J, et al. Deficiency or inhibition of oxygen sensor Phd1 induces hypoxia tolerance by reprogramming basal metabolism. Nat Genet. 2008; 40:170-180. [PubMed: 18176562]

26. Fendt SM, et al. Metformin decreases glucose oxidation and increases the dependency of prostate cancer cells on reductive glutamine metabolism. Cancer Res. 2013; 73:4429-4438. [PubMed: 23687346]

27. Antoniewicz MR, Kelleher JK, Stephanopoulos G. Elementary metabolite units (EMU): a novel framework for modeling isotopic distributions. Metab Eng. 2007; 9:68-86. [PubMed: 17088092]

28. Fernandez CA, Des Rosiers C, Previs SF, David F, Brunengraber H. Correction of $13 \mathrm{C}$ mass isotopomer distributions for natural stable isotope abundance. J Mass Spectrom. 1996; 31:255262. [PubMed: 8799277]

29. Nanchen A, Fuhrer T, Sauer U. Determination of metabolic flux ratios from 13C-experiments and gas chromatography-mass spectrometry data: protocol and principles. Methods Mol Biol. 2007; 358:177-197. [PubMed: 17035687]

30. Wilson PM, et al. A novel fluorescence-based assay for the rapid detection and quantification of cellular deoxyribonucleoside triphosphates. Nucl Acids Res. 2011; 39:e112. [PubMed: 21576234]

31. Sakaue-Sawano A, et al. Visualizing spatiotemporal dynamics of multicellular cell-cycle progression. Cell. 2008; 132:487-498. [PubMed: 18267078]

32. Millard P, Letisse F, Sokol S, Portais JC. IsoCor: correcting MS data in isotope labeling experiments. Bioinformatics. 2012; 28:1294-1296. [PubMed: 22419781]

33. Buscher JM, Czernik D, Ewald JC, Sauer U, Zamboni N. Cross-platform comparison of methods for quantitative metabolomics of primary metabolism. Anal Chem. 2009; 81:2135-2143. [PubMed: 19236023]

34. Benedito R, et al. The notch ligands Dll4 and Jagged1 have opposing effects on angiogenesis. Cell. 2009; 137:1124-1135. [PubMed: 19524514]

35. Scott A, Fruttiger M. Oxygen-induced retinopathy: a model for vascular pathology in the retina. Eye. 2010; 24:416-421. [PubMed: 20010791] 
shCPT1 RNA sequence 1: GCCATGAAGCTCTTAGACAAA shCPT1 RNA sequence 2: CGATGTTACGACAGGTGGTTT shACADVL RNA sequence: GCAGACATCTTCACGGTCTTT siCPT1a RNA sequence (from IDT trifecta): AGCUCUUAGACAAAUC/ AGAGAGAUAGAUUUGU 

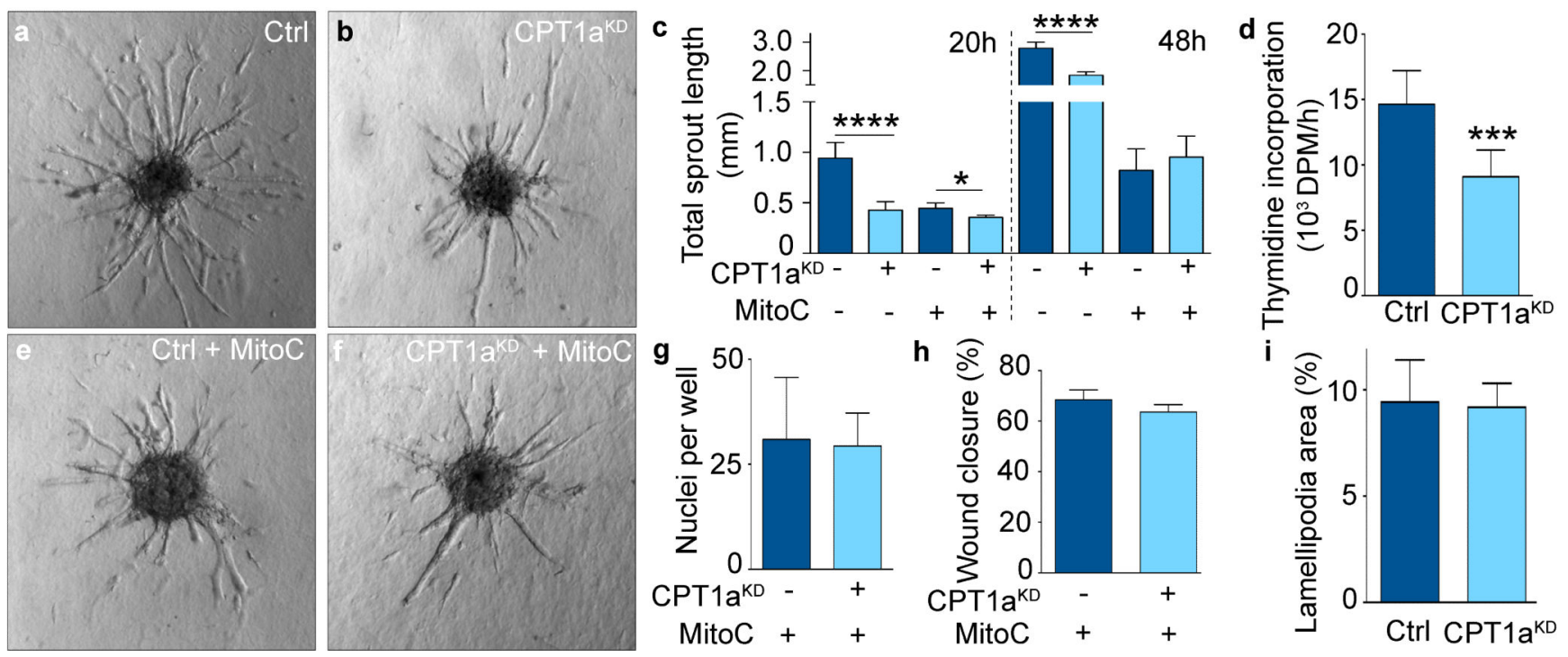

Figure 1. FAO stimulates vessel sprouting via EC proliferation

a,b, Representative images of control (ctrl) and CPT1a ${ }^{\mathrm{KD}} \mathrm{EC}$ spheroids. c, Total sprout length in control and CPT1 $1 \mathrm{a}^{\mathrm{KD}} \mathrm{EC}$ spheroids treated with mitomycin $\mathrm{C}$ (MitoC) when indicated $(n=3)$. d, $\left[{ }^{3} \mathrm{H}\right]$-thymidine incorporation in DNA in control and CPT1a ${ }^{\mathrm{KD}} \mathrm{ECs}$ $(\mathrm{n}=5)$. e,f, Representative images of MitoC-treated control and CPT1 $\mathrm{a}^{\mathrm{KD}} \mathrm{EC}$ spheroids. $\mathbf{g}$, Number of MitoC-treated control and CPT1 ${ }^{\mathrm{KD}}$ ECs that traversed a Boyden chamber $(\mathrm{n}=4$; $\mathrm{p}=\mathrm{NS})$. h, Scratch wound assay using MitoC-treated control and CPT1a ${ }^{\mathrm{KD}} \mathrm{ECs}(\mathrm{n}=4$; $\mathrm{p}=\mathrm{NS})$. $\mathbf{i}$, Lamellipodial area in control and CPT1 $\mathrm{a}^{\mathrm{KD}} \mathrm{ECs}(\mathrm{n}=4 ; \mathrm{p}=\mathrm{NS})$. Data are mean \pm s.e.m. of $\mathrm{n}$ independent experiments. Statistical test: mixed models (c,d,g-i). NS, not significant. $* \mathrm{p}<0.05, * * * \mathrm{p}<0.001, * * * * \mathrm{p}<0.0001$. 

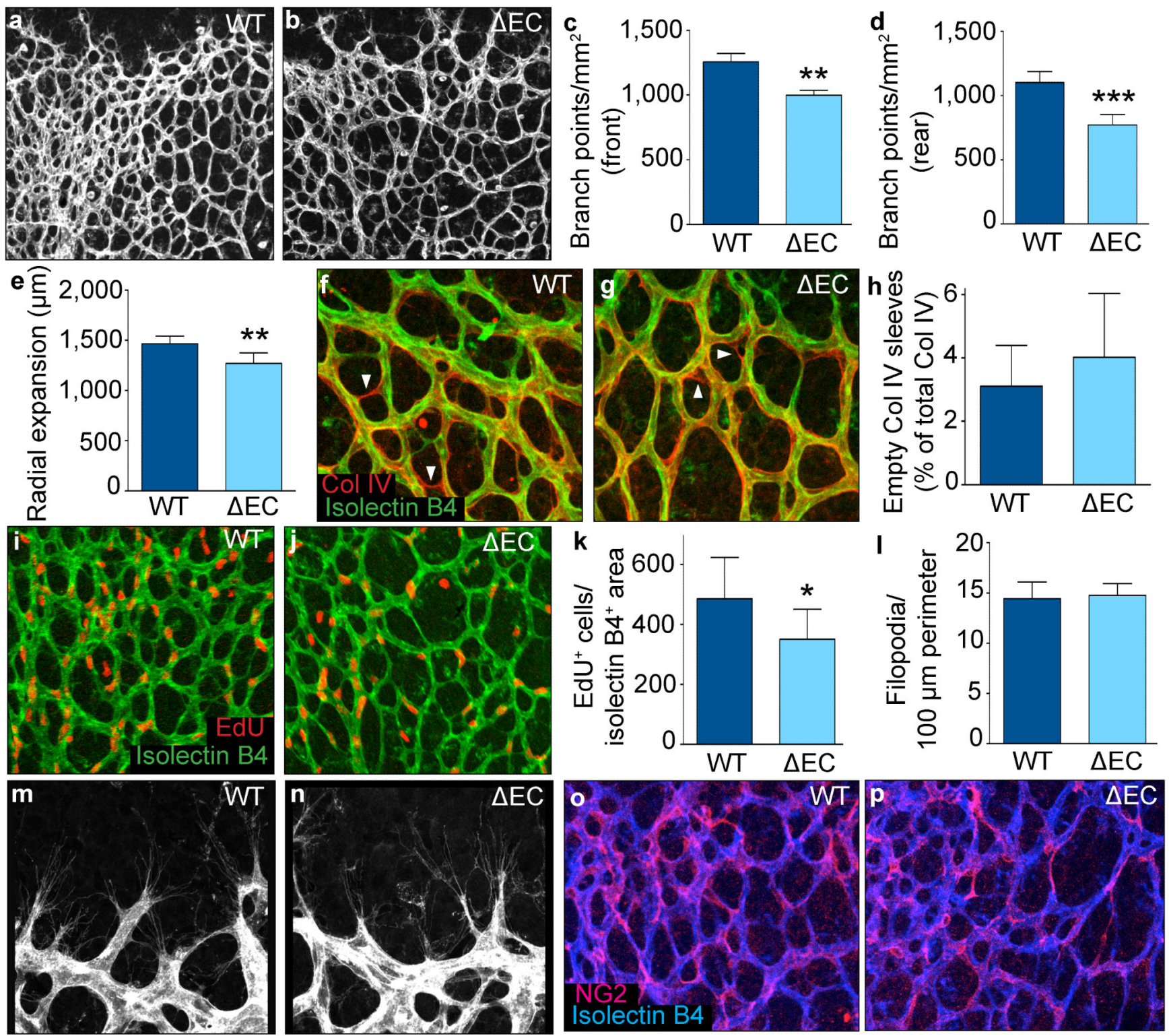

Figure 2. CPT1a gene deletion in ECs causes vascular defects in vivo

$\mathbf{a}, \mathbf{b}$, Representative images of retinal vessels of wild-type (a) and CPT1 $\mathrm{a}^{\mathrm{AEC}}$ (b) mice. $\mathbf{c}, \mathbf{d}$, Branch point quantification in WT and CPT1 $\mathrm{a}^{\mathrm{AEC}}$ mice in the front (c) and rear (d) of the retinal vasculature (5 litters, $\mathrm{n}=11$ pups for $\mathrm{WT}$ and $\left.\mathrm{CPT} 1 \mathrm{a}^{\mathrm{AEC}}\right)$. e, Retinal vascular outgrowth in WT and CPT1 $\mathrm{a}^{\Delta \mathrm{EC}}$ mice (6 litters, $\mathrm{n}=13$ pups for $\mathrm{WT}$ and 18 for $\mathrm{CPT} 1 \mathrm{a}^{\mathrm{AEC}}$ ).

$\mathbf{f , g}$, Representative images of the retina stained for isolectin-B4 (green) and collagen IV (red) in WT (f) and CPT1 $\mathrm{a}^{\Delta \mathrm{EC}}$ mice (g). $\mathbf{h}$, Quantification of isolectin-B4- collagen $\mathrm{IV}^{+}$ empty sleeves in WT and CPT1 $\mathrm{a}^{\Delta \mathrm{EC}}$ pups ( 4 litters, $\mathrm{n}=8$ pups for WT and 14 for $\mathrm{CPT} 1 \mathrm{a}^{\Delta \mathrm{EC}}$; $\mathrm{p}=\mathrm{NS}$ ). $\mathbf{i}, \mathbf{j}$, Representative images of retina stained for EdU (red) and isolectin-B4 (green) in WT (i) and CPT1 $\mathrm{a}^{\triangle \mathrm{EC}}$ (j) mice. $\mathbf{k}$, Quantification of EdU ${ }^{+} \mathrm{ECs}$ in $\mathrm{WT}$ and $\mathrm{CPT} 1 \mathrm{a}^{\triangle \mathrm{EC}}$ mice ( 3 litters, $n=9$ pups for WT and 6 for CPT1 $\mathrm{a}^{\Delta \mathrm{EC}}$ ). 1 , Quantification of filopodia in WT and $\mathrm{CPT}_{1} \mathrm{a}^{\Delta \mathrm{EC}}$ mice ( 6 litters, $\mathrm{n}=20$ pups for $\mathrm{WT}$ and 16 for $\left.\mathrm{CPT} \mathrm{a}^{\Delta \mathrm{EC}} ; \mathrm{p}=\mathrm{NS}\right) . \mathbf{m}, \mathbf{n}$, 
Representative images of filopodia in WT (m) and CPT1 $\mathrm{a}^{\Delta \mathrm{EC}}$ (n) mice. o,p, Representative images of the retinal vasculature of WT (o) and CPT1 $\mathrm{a}^{\triangle \mathrm{EC}}$ mice (p) stained for isolectin-B4 (blue) and the pericyte marker NG2 (pink). Data are mean \pm s.e.m. of $\mathrm{n}$ individual mice.

Statistical test: mixed models (c-e,h,k,l). NS, not significant. *p $<0.05,{ }^{* *} \mathrm{p}<0.01$, $* * * \mathrm{p}<0.001$. 

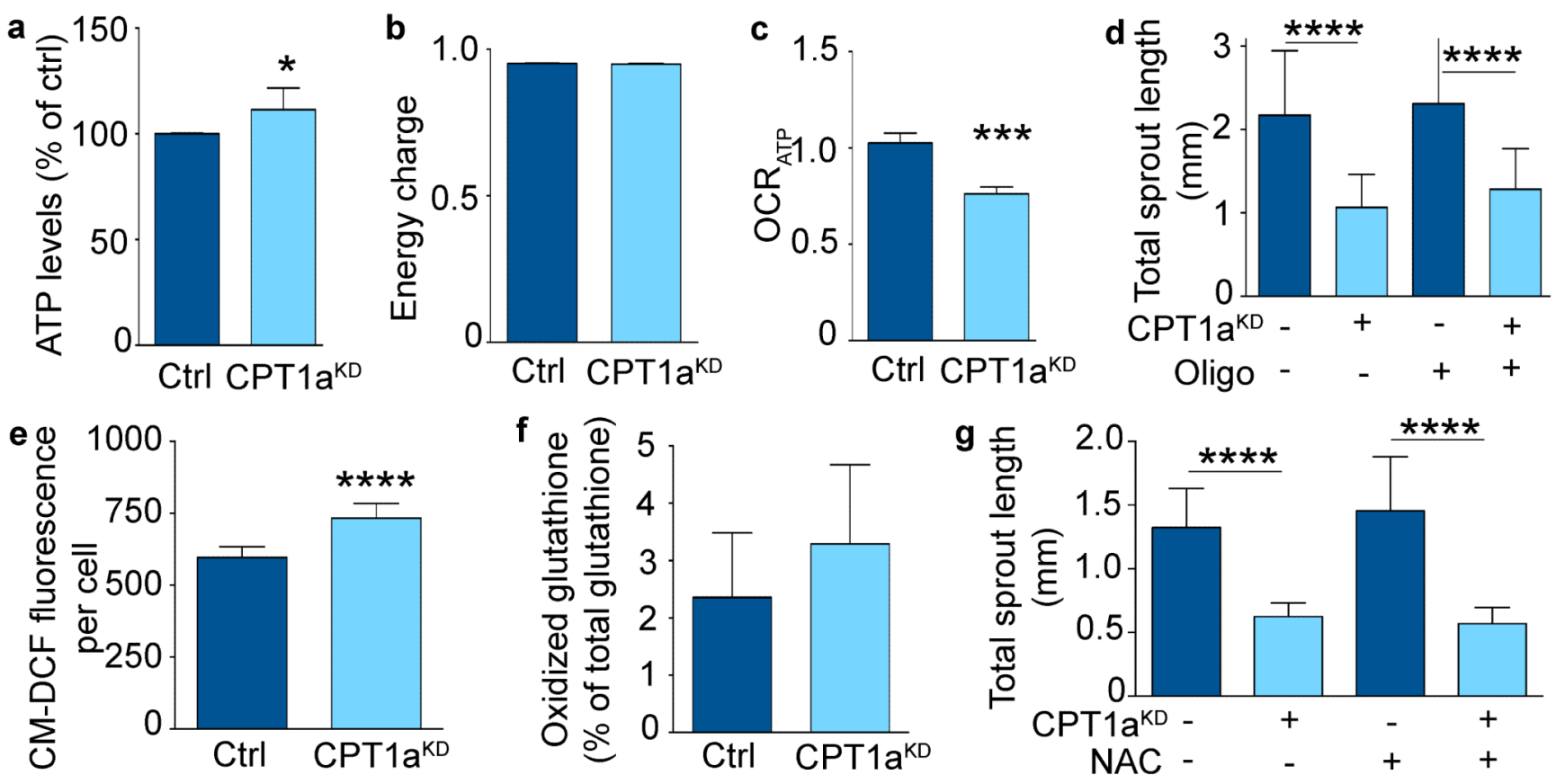

Figure 3. CPT1a silencing does not cause ATP depletion or redox imbalance a, Intracellular ATP levels in control and CPT1a KD ECs $(n=4)$. b, Energy charge measurement in control and CPT $1 \mathrm{a}^{\mathrm{KD}}$ ECs $(\mathrm{n}=3 ; \mathrm{p}=\mathrm{NS})$. $\mathbf{c}$, ATP coupled oxygen consumption rate $\left(\mathrm{OCR}_{\mathrm{ATP}}\right)$ in control and $\mathrm{CPT} 1 \mathrm{a}^{\mathrm{KD}} \mathrm{ECs}(\mathrm{n}=3)$. d, Total sprout length upon oligomycin (oligo) treatment in control and CPT1 $\mathrm{a}^{\mathrm{KD}} \mathrm{EC}$ spheroids $(\mathrm{n}=3)$. e, Intracellular ROS measurement in control and CPT1 $\mathrm{a}^{\mathrm{KD}} \mathrm{ECs}(\mathrm{n}=6)$. f, Oxidized glutathione levels as percent of total glutathione, in control and CPT1 ${ }^{\mathrm{KD}} \mathrm{EC}(\mathrm{n}=3 ; \mathrm{p}=\mathrm{NS})$. g, Total sprout length upon NAC treatment in control and CPT $1 \mathrm{a}^{\mathrm{KD}} \mathrm{EC}$ spheroids $(\mathrm{n}=3)$. Data are mean \pm s.e.m of $n$ independent experiments. Statistical test: mixed models (a-g). NS, not significant. $* \mathrm{p}<0.05, * * * \mathrm{p}<0.001, * * * * \mathrm{p}<0.0001$. 

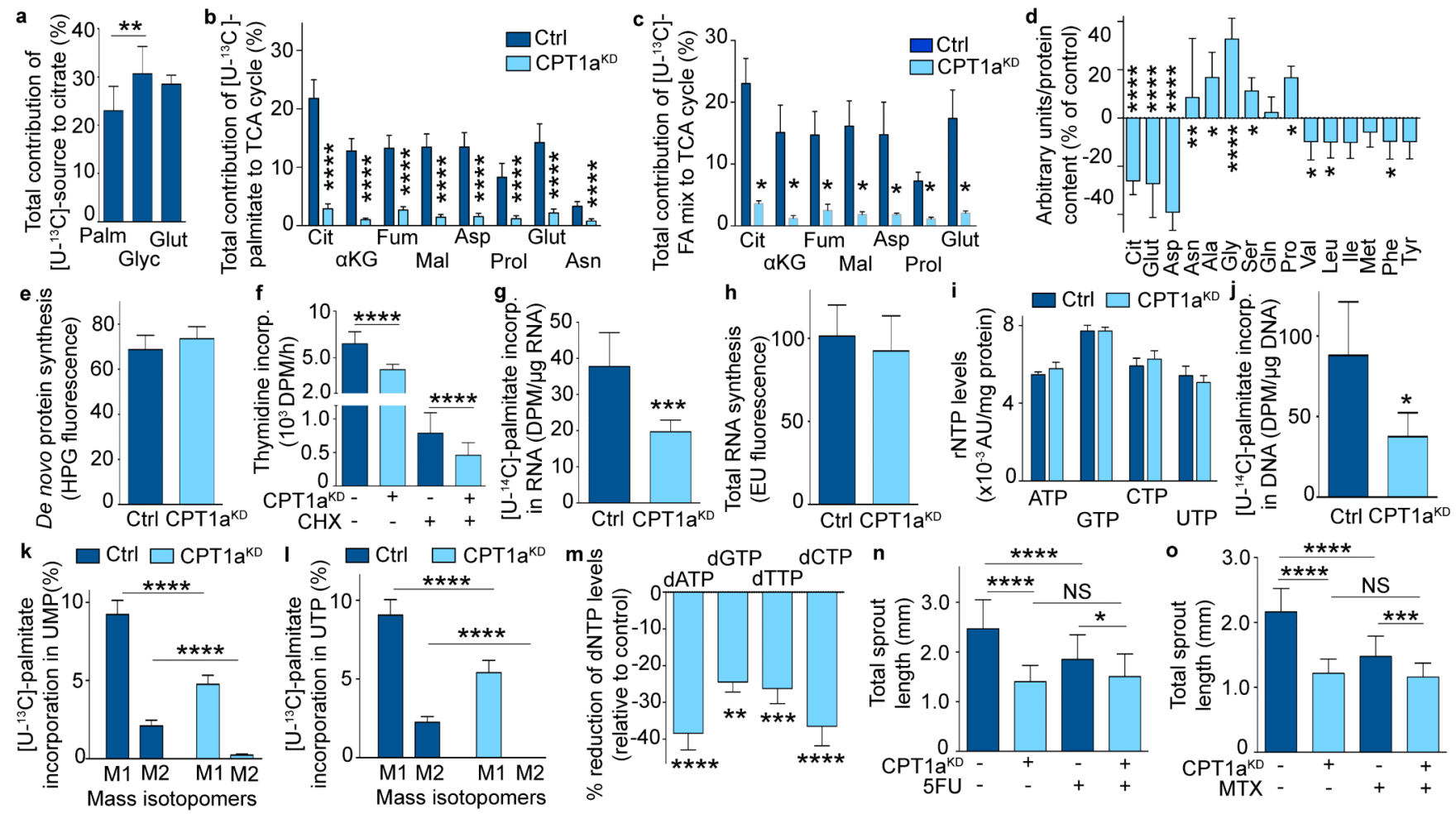

Figure 4. CPT1a silencing reduces TCA replenishment and FAO is used for nucleotide synthesis a, Total contribution of $\left[\mathrm{U}_{-}{ }^{13} \mathrm{C}\right]$-palmitate (palm), [U- $\left.{ }^{13} \mathrm{C}\right]$-glucose $(\mathrm{glyc})$, and $\left[\mathrm{U}_{-}{ }^{13} \mathrm{C}\right]-$ glutamine (glut) to citrate $(\mathrm{n}=3)$. b,c, Total contribution of $\left[\mathrm{U}_{-}{ }^{13} \mathrm{C}\right]$-palmitate $(\mathrm{b})$ or $\left[\mathrm{U}-{ }^{13} \mathrm{C}\right]-$ algal fatty acid (FA) mix (c) to citrate (cit), a-ketoglutarate ( $\mathrm{aKG}$ ), fumarate (fum), malate (mal), aspartate (asp), proline (prol), glutamate (glut) or asparagine (asn) in control and CPT1 $1 \mathrm{a}^{\mathrm{KD}}$ ECs ( $\mathrm{n}=7$ for TCA intermediates and $\mathrm{n}=3-5$ for amino acids in $\mathrm{b} ; \mathrm{n}=3$ in $\mathrm{c}$ ). $\mathbf{d}$, Intracellular content of citrate (cit), glutamate (glut), aspartate (asp), glutamine (gln), isoleucine (ile), methionine (met), tyrosine (tyr), asparagine (asn), alanine (ala), glycine (gly), serine (ser), proline (pro), valine (val), leucine (leu) and phenylalanine (phe) in control and CPT1 $1 \mathrm{a}^{\mathrm{KD}} \mathrm{ECs}$ ( $\mathrm{n}=8$ for cit and asp, $\mathrm{n}=6$ for glut, $\mathrm{n}=4$ for asn and ser, $\mathrm{n}=5$ for ala, gly, gln, pro, val, leu, ile, met, phe and tyr). e, De novo protein synthesis in control and CPT1a ${ }^{\mathrm{KD}}$ ECs $(n=3 ; p=N S) . \mathbf{f},\left[{ }^{3} \mathrm{H}\right]$-thymidine incorporation upon cycloheximide $(\mathrm{CHX})$ treatment in control and CPT1 ${ }^{\mathrm{KD}} \mathrm{ECs}(\mathrm{n}=3)$. g, [U- $\left.{ }^{14} \mathrm{C}\right]$-palmitate incorporation into RNA in control and CPT1a ${ }^{\mathrm{KD}}$ ECs $(\mathrm{n}=5)$. h, De novo RNA synthesis in control and CPT1 ${ }^{\mathrm{KD}} \mathrm{ECs}(\mathrm{n}=3$; $\mathrm{p}=\mathrm{NS})$. $\mathbf{i}$, Intracellular levels of the rNTPs in control and CPT $1 \mathrm{a}^{\mathrm{KD}} \mathrm{ECs}(\mathrm{n}=4 ; \mathrm{p}=\mathrm{NS})$. AU: arbitrary units. $\mathbf{j}$, [U- $\left.{ }^{14} \mathrm{C}\right]$-palmitate incorporation into DNA in control and CPT1 $\mathrm{a}^{\mathrm{KD}} \mathrm{ECs}$ $(\mathrm{n}=5) . \mathbf{k}, \mathbf{l}, \% \mathrm{M} 1$ and M2 labeling from $\left[\mathrm{U}^{13} \mathrm{C}\right]$-palmitate in UMP (k) and UTP (1) in control and CPT1 ${ }^{\mathrm{KD}}$ ECs $(\mathrm{n}=5)$. $\mathbf{m}$, Reduction of intracellular dNTP levels in CPT1a ${ }^{\mathrm{KD}}$ versus control ECs ( $\mathrm{n}=5$ for dATP and dCTP, $\mathrm{n}=4$ for dTTP and $\mathrm{dGTP}$ ). $\mathbf{n , o}$, Total sprout length upon 5-fluorouracil (5FU) (n) or methotrexate (MTX) (o) treatment in control and CPT1 ${ }^{\mathrm{KD}}$ ECs $(\mathrm{n}=4)$. Data are mean \pm s.e.m of $\mathrm{n}$ independent experiments. Statistical test: mixed models (a-o). NS, not significant. $* \mathrm{p}<0.05, * * \mathrm{p}<0.01, * * * \mathrm{p}<0.001, * * * * \mathrm{p}<0.0001$. 

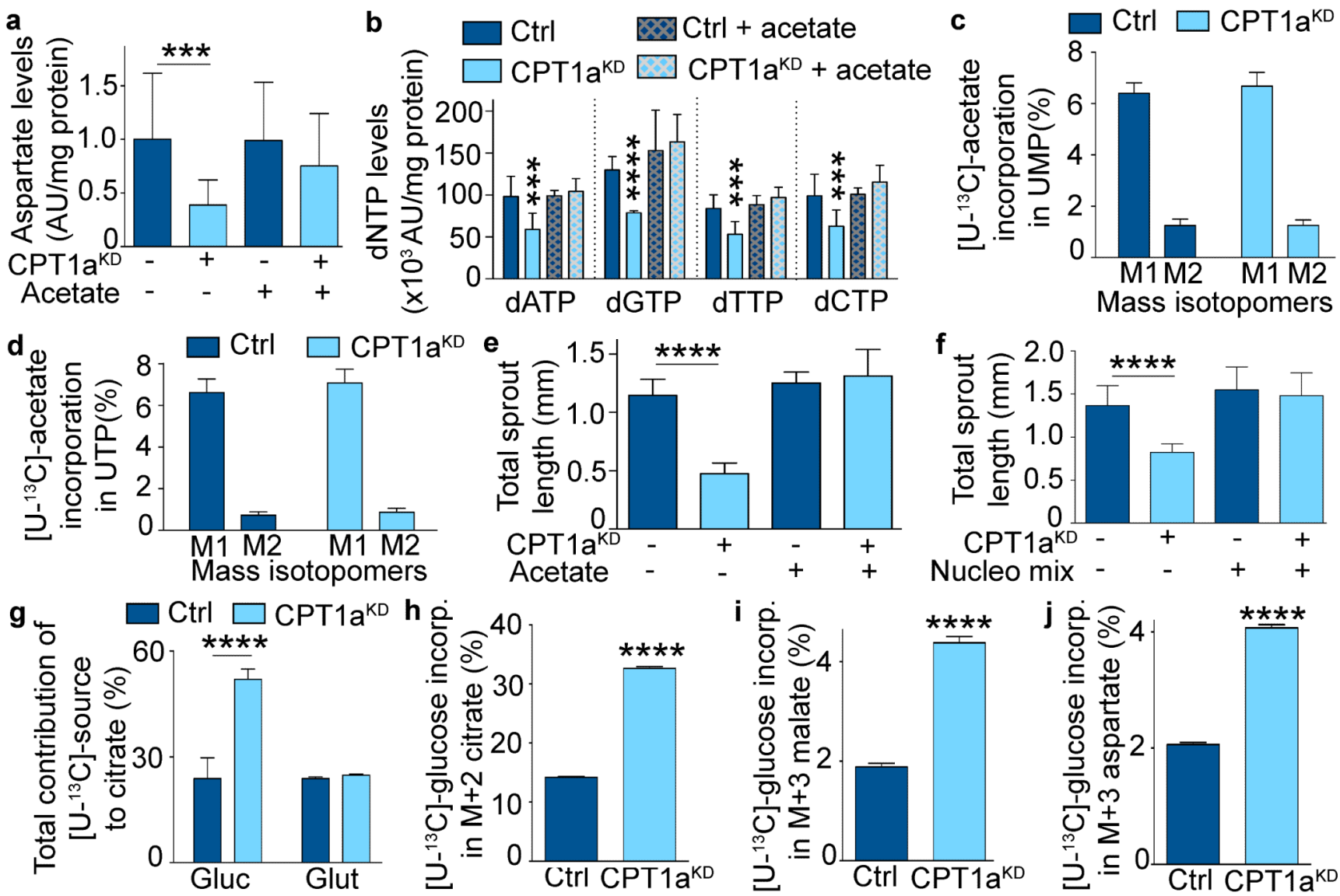

Figure 5. Acetate or nucleosides rescue the $\mathrm{CPT1} \mathrm{a}^{\mathrm{KD}}$ sprouting defect

a, Intracellular aspartate levels upon acetate supplementation in control and CPT1 ${ }^{\mathrm{KD}} \mathrm{ECs}$ $(n=3)$. AU: arbitrary units. b, Intracellular levels of the indicated dNTPs upon acetate supplementation in control and CPT1 ${ }^{\mathrm{KD}} \mathrm{ECs}(\mathrm{n}=3) . \mathbf{c}, \mathbf{d}, \% \mathrm{M} 1$ and M2 labeling from $\left[\mathrm{U}-{ }^{13} \mathrm{C}\right]$-acetate in UMP (c) and UTP (d) in control and CPT1 ${ }^{\mathrm{KD}}$ ECs $(\mathrm{n}=5 ; \mathrm{p}=\mathrm{NS})$. e, Total sprout length upon acetate supplementation in control and CPT1 ${ }^{\mathrm{KD}}$ EC spheroids $(\mathrm{n}=3) . \mathbf{f}$, Total sprout length upon nucleoside mix supplementation in control and CPT1 ${ }^{\mathrm{KD}} \mathrm{EC}$ spheroids $(n=4)$. g, Total contribution of $\left[\mathrm{U}_{-}{ }^{13} \mathrm{C}\right]$-glucose and $\left[\mathrm{U}_{-}{ }^{13} \mathrm{C}\right]$-glutamine to citrate in control and CPT1a ${ }^{\mathrm{KD}} \mathrm{ECs}(\mathrm{n}=3) . \mathbf{h}, \% \mathrm{M}+2$ labeled citrate from [U- $\left.{ }^{13} \mathrm{C}\right]$-glucose in control and CPT1 $1 \mathrm{a}^{\mathrm{KD}} \mathrm{ECs}(\mathrm{n}=3) . \mathbf{i}, \mathbf{j}, \% \mathrm{M}+3$ labeled malate (i) and aspartate (j) from $\left[\mathrm{U}^{13} \mathrm{C}\right]$-glucose in control and CPT1a ${ }^{\mathrm{KD}} \mathrm{ECs}(\mathrm{n}=3)$. Data are mean \pm s.e.m of $\mathrm{n}$ independent experiments. Statistical test: mixed models (a-j). NS, not significant. $* * * \mathrm{p}<0.001, * * * * \mathrm{p}<0.0001$. 


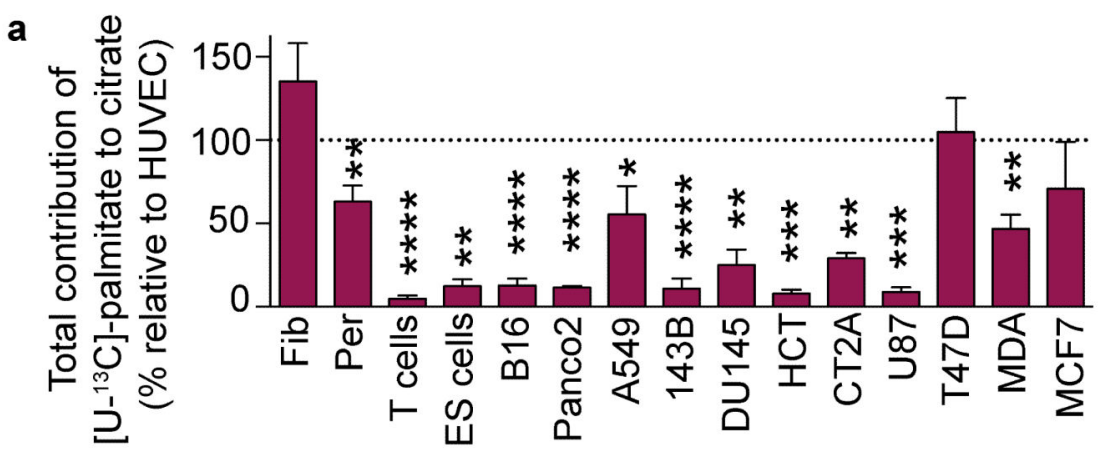

b
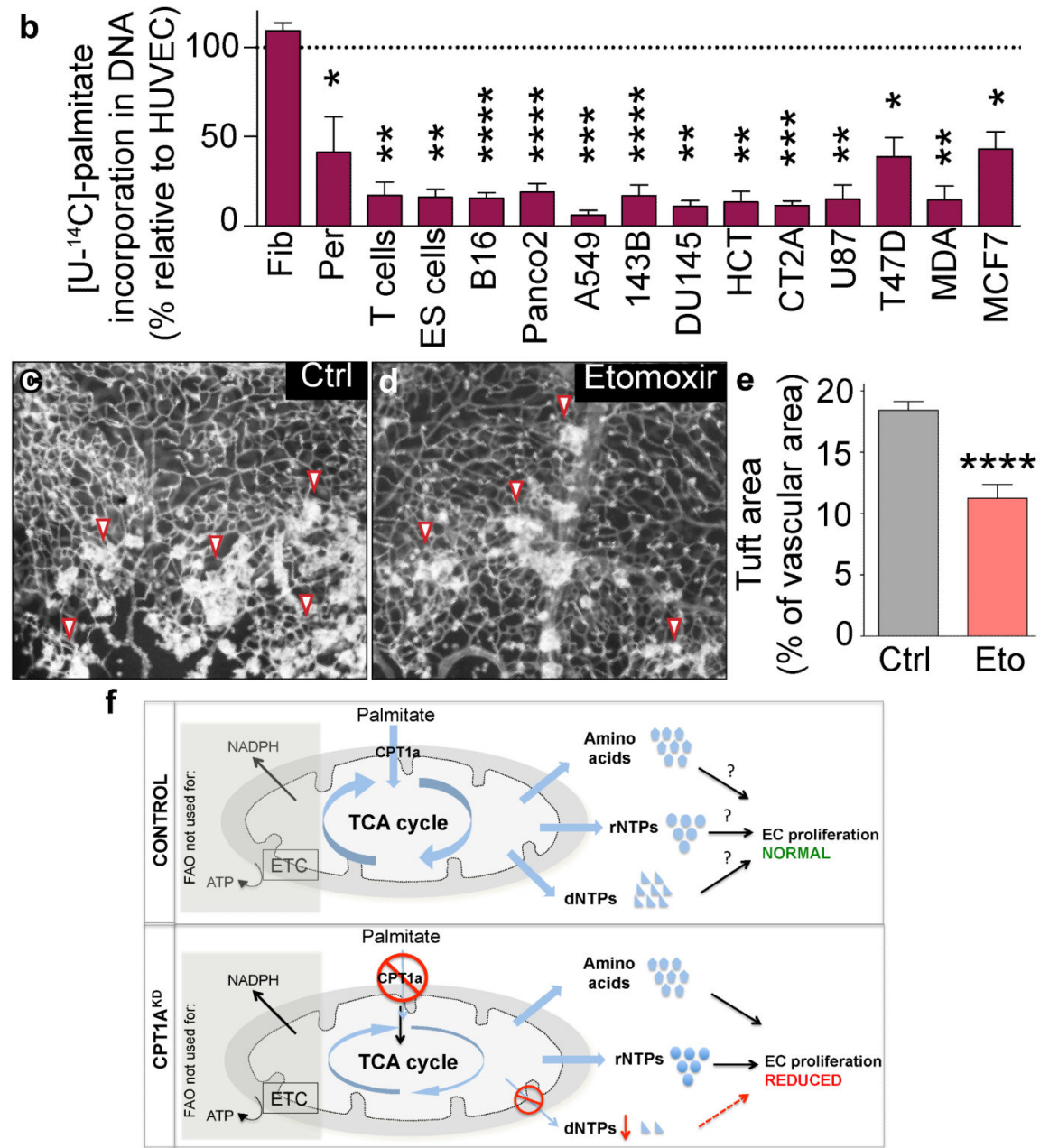

Figure 6. Most other cell types do not use FA carbons for dNTP synthesis and inhibition of CPT1a impairs angiogenesis

a, Total contribution of [U- $\left.{ }^{13} \mathrm{C}\right]$-palmitate to citrate in various primary cells and cancer cell lines, expressed relative to the value in ECs ( $\mathrm{n}=9$ for ECs, $\mathrm{n}=8$ for pericytes (per), $\mathrm{n}=6$ for $\mathrm{T}$ cells, B16, A549 and 143B, n=5 for PancO2, $n=4$ for DU145, T47D and MDA, $n=3$ for fibroblasts (fib), ES cells, HCT, CT2A, U87 and MCF7). b, Contribution of [U- $\left.{ }^{14} \mathrm{C}\right]-$ palmitate to DNA, expressed relative to the value in ECs ( $n=14$ for ECs, $n=6$ for pericytes (per), $\mathrm{n}=5$ for B16, Panco 2 and A549, $\mathrm{n}=4$ for fibroblasts (fib), T47D, 143B and T cells, $\mathrm{n}=3$ for HCT, MDA, DU145, U87, CT2A, MCF7 and ES cells). c,d, Representative images of 
retinal flat-mounts of ROP mice treated with vehicle (c) or etomoxir (eto) (d). e, Vascular tuft area in control and etomoxir-treated pups ( $\mathrm{n}=13$ for WT and 9 for etomoxir). $\mathbf{f}$, Mechanistic model. Top - control ECs: Uptake of palmitate and FAO in ECs are not essential for the production of ATP and NADPH (indicated in the shaded box), but fatty acid-derived carbons are incorporated in amino acids, and in precursors of rNTPs and dNTPs; how critically these pathways regulate EC proliferation cannot be assessed in control cells (denoted by question mark). Bottom - CPT1 ${ }^{\mathrm{KD}}$ ECs: Silencing of CPT1a reveals however that decreasing FAO depletes dNTP pools, without affecting rNTP and protein synthesis, implying that fatty acids are irreplaceable for DNA synthesis; since de novo synthesis of dNTPs is critical for DNA replication, CPT1a silencing impairs EC proliferation. Data are mean \pm s.e.m of $n$ independent experiments $(a, b)$ or the total number of mice (of 4 litters) (e). Statistical test: two-sided $t$-test (a,b); mixed models (e). NS, not significant. $* \mathrm{p}<0.05, * * \mathrm{p}<0.01, * * * \mathrm{p}<0.001, * * * * \mathrm{p}<0.0001$. 